\title{
Microtubule-associated Protein 1 Light Chain 3 Is a Fibronectin mRNA-binding Protein Linked to mRNA Translation in Lamb Vascular Smooth Muscle Cells
}

\author{
Bin Zhou, ${ }^{* \ddagger \S}$ Nancy Boudreau, ${ }^{\star \neq \S}$ Claire Coulber, ${ }^{\star \neq \S}$ James Hammarback,, and Marlene Rabinovitch ${ }^{\star \neq \S}$ \\ *Division of Cardiovascular Research, Research Institute, The Hospital for Sick Children, and ${ }^{\ddagger}$ Department of Pediatrics and ${ }^{\S}$ Department \\ of Pathology, University of Toronto, Toronto, Ontario, M5G 1X8, Canada; and "Department of Neurobiology and Anatomy, Bowman \\ Gray School of Medicine, Winston-Salem, North Carolina 27157-1010
}

\begin{abstract}
Intimal cushions form in the fetal ductus arteriosus by fibronectin-dependent smooth muscle cell migration which is associated with greater efficiency of fibronectin mRNA translation. We investigated whether the AU-rich element (ARE), UUAUUUAU, in the $3^{\prime}$-untranslated region ( $3^{\prime} U T R$ ) of fibronectin mRNA is involved in this mechanism by transfecting smooth muscle cells with plasmids containing the chloramphenicol acetyltransferase coding region with its 3'UTR replaced by fibronectin $3^{\prime}$ UTR bearing intact or mutated ARE. More efficient translation of fusion mRNA with intact versus mutated ARE was observed. This effect was amplified in ductus (10.9-fold) compared with nonmigratory, lower fibronectin-producing aorta cells (6.5-fold). Ductus cells transfected with wild-type but not ARE-mutated plasmid reverted to the stellate phenotype of aorta cells associated with reduced fibronectin production. This suggested that plasmid ARE sequesters RNA-binding factors, thereby reducing endogenous fibronectin mRNA translation. We next purified a $15-\mathrm{kD}$ fibronectin ARE-dependent RNAbinding protein and identified it as microtubule-associated protein 1 light chain 3 (LC3). LC3 is present in greater amounts in ductus compared with aorta cells, and overexpression of LC3 in aortic cells by transfection enhances fibronectin mRNA translation to levels observed in ductus cells. (J. Clin. Invest. 1997. 100:3070-3082.) Key words: ductus arteriosus • extracellular matrix protein • cell migration • transfection $\cdot$ protein purification
\end{abstract}

\section{Introduction}

During late gestation, the fetal ductus arteriosus (DA) ${ }^{1}$ undergoes morphologic changes leading to the formation of intimal cushions in animal species (1) and in humans (2, 3). These structures are characterized by smooth muscle cell (SMC) mi-

Address correspondence to Marlene Rabinovitch, M.D., Division of Cardiovascular Research, Hospital for Sick Children, 555 University Avenue, Toronto, ON, Canada M5G 1X8. Phone: 416-813-5918; FAX: 416-813-7480; E-mail: mr@sickkids.on.ca N. Boudreau's current address is Department of Anatomy, Medical College of Virginia, 1107 E. Marshall Street, Rm. 9060, Sanger Hall Medical College, Richmond, VA 23298. 1997.

Received for publication 22 July 1997 and accepted 13 October

J. Clin. Invest.

(C) The American Society for Clinical Investigation, Inc. 0021-9738/97/12/3070/13 \$2.00

Volume 100, Number 12, December 1997, 3070-3082

http://www.jci.org gration from the inner media of the vessel wall into a subendothelial space enriched in glycosaminoglycans. The cushions partially occlude the vessel lumen and assure that it closes completely when it constricts postnatally. By comparison with aorta (Ao) SMC, we observed in vitro that the elongated migratory phenotype of DA SMC was dependent on their increased synthesis of fibronectin $(\mathrm{FN})(4,5)$. This feature was not associated with increased FN mRNA levels or mRNA stability or with differences in FN mRNA splicing (6), suggesting enhanced translational efficiency of FN mRNA in DA versus Ao SMC.

FN, a large extracellular matrix glycoprotein with a relative molecular mass of $220,000 \mathrm{kD}$, functions as a molecule involved in cell adhesion, migration, and differentiation (7). FN synthesis is regulated by growth factors or hormones $(8,9)$ through increasing mRNA levels or by alternative splicing of mRNA $(10,11)$. Posttranscriptional mechanisms other than mRNA alternative splicing, such as enhanced mRNA translation (12) or increased mRNA stability (13-15) also appear to regulate $\mathrm{FN}$ protein production.

Regulatory elements in the $5^{\prime}$ - as well as the $3^{\prime}$-untranslated region (UTR) of mRNA may modulate mRNA stability and translational efficiency (16). Caput et al. (17) reported a consensus sequence (UUAUUUAU) present in the $3^{\prime} \mathrm{UTR}$ of many cytokine-derived mRNAs, such as TNF- $\alpha$, GM-CSF, IL-1, and IFN, and protooncogene-derived mRNAs, such as c-myc and c-fos. This sequence is also present in the $3^{\prime} \mathrm{UTR}$ of FN mRNA of different animal species (17-19). In most studies, this AU-rich element (ARE) in the $3^{\prime} \mathrm{UTR}$ of labile mRNAs, such as c-myc (20), GM-CSF (21), and c-fos $(22,23)$, correlates with rapid mRNA turnover. However, the ARE also regulates mRNA translation (24-27). Recent studies have indicated that degradation of mRNA mediated by the ARE is coupled with ongoing translation (28-30).

Trans-acting factors in the cytoplasm may alter mRNA stability and translational efficiency through binding to specific consensus sequences such as the ARE described above. Malter (31) first reported cytosolic proteins, termed adenosine-uridine binding factors (AUBFs), which bind specifically to AUUUA motifs. Bohjanen et al. (32) identified three factors that bind to the ARE with different affinities and specificities. Since then, several ARE-binding factors have been purified or cloned in different tissues or cells (33-36).

1. Abbreviations used in this paper: Ao, aorta; ARE, AU-rich element; AUBF, adenosine-uridine binding factor; $\beta$-gal, $\beta$-galactosidase; $\beta$-ME, $\beta$-mercaptoethanol; CAT, chloramphenicol acetyltransferase; DA, ductus arteriosus; DAPI, 4',6-diamidino-2-phenylindole; FN, fibronectin; GST, glutathione $S$-transferase; IP, irrelevant probe; LC, light chain; MAP, microtubule-associated protein; $N$-EM, $N$-ethylmaleimide; nt, nucleotide(s); PVDF, polyvinyldifluoride; SMC, smooth muscle cell(s); SP, specific probe; TBS, Tris-buffered saline; UTR, untranslated region. 
The ARE found in the 3'UTR of FN mRNA may also function to modulate SMC FN mRNA stability and translation. In this study, we show that the ARE in the $3^{\prime}$ UTR of FN mRNA is of functional significance in enhancing mRNA translation in vascular SMC. We have isolated three ARE-binding complexes with relative molecular masses of $\sim 60,000,30,000$, and $15,000 \mathrm{kD}$ and further purified and identified the $15-\mathrm{kD}$ ARE-binding protein as light chain (LC) 3 of microtubuleassociated protein (MAP) 1 (37). We demonstrate an increase in LC3 levels in the cytosol of DA compared with Ao SMC. Furthermore, overexpression of LC3 in Ao SMC increases FN mRNA translation to the levels observed in DA SMC. Therefore, this study shows that LC3, a MAP described in brain, is also present in vascular SMC. We provide the first evidence for its RNA-binding properties, and elucidate its functional effect related to translation of FN mRNA.

\section{Methods}

Cell culture. Primary DA and Ao SMC cultures were prepared from fetal lamb tissues as described previously (38). SMC were cultured in medium 199 (GIBCO BRL, Gaithersburg, MD) with 10\% FBS (GIBCO BRL). In serum-stimulation experiments, cells were serumstarved for $20 \mathrm{~h}$ followed by adding $20 \%$ FBS for $4 \mathrm{~h}$, while control cells were serum-starved for $24 \mathrm{~h}$.

Plasmid constructs, site-directed mutagenesis, and in vitro transcription. Three chloramphenicol acetyltransferase (CAT) reporter constructs were made for in vitro transfection studies. Plasmid $p E C E-$ CAT was generated by insertion of a BglII-KpnI fragment from pBLCAT2 (39) containing full-length CAT cDNA and SV40 small $t$ intron into the same unique site of pECE (40) in the correct orientation with respect to the SV40 early promoter. Plasmid pECE-CAT-FN, which included the FN 3'UTR, was constructed in several steps. The CAT cDNA without its $3^{\prime}$ UTR was obtained by digesting pBL-CAT2 with BglII and ScaI, and the coding sequence was repaired using synthetic oligonucleotides flanked upstream by a ScaI site and downstream immediately after the stop codon by a HindIII site. This fulllength CAT coding sequence was inserted into pECE at the BglII and HindIII sites, and the plasmid was named pECE-CAT $3^{\prime} \mathrm{UTR}^{-}$. A 717-bp KpnI-EcoRI rat FN fragment from a plasmid SP65 (pFN) (kindly provided by Dr. R. Hynes, Center for Cancer Research, Massachusetts Institute of Technology, Cambridge, MA) containing the full-length 3'UTR of FN except for a 60-bp sequence upstream of the polyadenylation signal and including a single-copy ARE, UUAUUUAU (which is 81 bp upstream from the $3^{\prime}$ flanking end), was inserted into pECE-CAT $3^{\prime} \mathrm{UTR}^{-}$at the same site downstream of the CAT coding sequence.

Site-directed mutation of the ARE was carried out using a PCR method. A pair of oligonucleotides carrying mismatched bp corresponding to the ARE was used. The upper primer was 5'-CCTGGGAGGGAGCAATTTTTCCC-3', and the lower primer was $5^{\prime}$ GCTCCCTCCCAGGTAAGAGAAAG-3' (mutated ARE shown in bold). A 5'-end primer, 5'-GTTCTGCTTTCTTTGC-3', located upstream of the mutated site and a downstream $3^{\prime}$-end primer, $5^{\prime}$-ATCAACTGCATACAAAG-3', were also used. A 199-bp product with mutated ARE was generated by PCR and subcloned into pECE at the SmaI site. A 170-bp PstI-XbaI fragment containing the mutated ARE was further released and used to replace the corresponding fragment within pECE-CAT-FN, and the new construct was designated pECE-CAT-FN $\Delta$. All constructs were confirmed by restriction enzyme mapping, and the mutation was verified by DNA sequencing.

Templates for in vitro synthesis of antisense RNA probes for RNase protection assays were as follows. pBSKS $^{-}$-CAT was constructed by ligating a 260-bp XhoI-EcoR1 CAT fragment from pBLCAT2 into the same sites of phagemid Bluescript II $\mathrm{KS}^{-}$(pBSKS $^{-}$; Stratagene Inc., La Jolla, CA). When linearized with XhoI and tran- scribed with T7 RNA polymerase, a full-length 329-nucleotide (nt) probe was generated, of which the protected CAT mRNA fragment was 260 nt. pBSKS $^{-}-\beta$-gal consisted of a 289 -bp ClaI-EcoRV fragment of $\beta$-galactosidase ( $\beta$-gal) from pSV- $\beta$-gal (Promega Corp., Madison, WI) which was cloned into the same sites of $\mathrm{pBSKS}^{-}$. When digested with XhoI and transcribed by T7 RNA polymerase, a full-length 377-nt probe was generated, of which the protected $\beta$-gal RNA fragment was $289 \mathrm{nt}$. The full-length 3'UTR containing wild or mutated ARE for use in gel mobility shift assays was obtained by insertion of the HindIII-XbaI fragment from pECE-CAT-FN or pECE-CAT-FN $\Delta$ into the same sites of pBSKS $^{-}$and transcribed by T3 RNA polymerase after linearization with XbaI.

All of the ${ }^{32} \mathrm{P}$-labeled RNAs were synthesized by in vitro transcription reactions in the presence of $\left[\alpha{ }^{32} \mathrm{P}\right] \mathrm{UTP}$. DNA templates were removed with DNase I digestion, and the full-length probes were obtained by $6 \%$ acrylamide/ $8 \mathrm{M}$ urea gel purification. ${ }^{32} \mathrm{P}$-labeled 18 -mer FN RNA oligonucleotides containing the ARE (in bold), 5'-ACCUGUUAUUUAUCAAUU-3', or irrelevant oligonucleotides from the FN coding region, 5'-AGAGCGGGAGCAGGAAGU-3', were generated by a method described previously (41).

Transfection and CAT assay. Transient transfection was performed using the calcium phosphate method (see pp. 33-37 in reference 42). $20 \mu \mathrm{g}$ of each CAT construct was used to transfect each 100 -mm dish. $5 \mu \mathrm{g}$ of the plasmid pSV- $\beta$-gal (Promega Corp.) was cotransfected with each experiment as a control for transfection efficiency. $\beta$-Gal activity was measured by colorimeter, and cell lysates containing similar amounts of activity were used for CAT assays with $\left[{ }^{14} \mathrm{C}\right]$ chloramphenicol and acetyl-CoA. The acetylated products were chromatographed on thin-layer plates in $95 \%$ chloroform $/ 5 \%$ methanol. The CAT activity was counted using a scintillation counter and expressed as percent conversion of total added $\left[{ }^{14} \mathrm{C}\right]$ chloramphenicol after correction for background. Additional experiments were carried out to improve efficiency of transfection with a component system, which included adenovirus, polylysine, and plasmid (43). The replicationdeficient human adenovirus type 5 mutant, Ad5dl312 (generously provided by Dr. Frank Graham, McMaster University, Hamilton, Ontario, Canada) was propagated in the human embryonic kidney cell line, HEK 293 (American Type Culture Collection, Rockville, MD), harvested, and purified as described previously (43). Cells at passage 1 were seeded onto $22-\mathrm{mm}^{2}$ glass coverslips in petri dishes at a density of $10^{6}$ cells, cultured for $24 \mathrm{~h}$ before transfection, and transfected with $5 \mu \mathrm{g}$ of each CAT construct. $3 \mathrm{~d}$ after transfection, the cells were fixed and stained for CAT or FN protein.

RNase protection assay. RNase protection assays were carried out using Ribonuclease Protection Assay kit II (Ambion Inc., Austin, TX) following the manufacturer's instructions. For each reaction, $8 \times$ $10^{4} \mathrm{cpm}$ probes were hybridized with $10 \mu \mathrm{g}$ total RNA overnight at $45^{\circ} \mathrm{C} .10 \mu \mathrm{g}$ yeast RNA was used as a negative control. The protected probes were separated on a $6 \%$ acrylamide/ $8 \mathrm{M}$ urea gel after RNase T1/RNase A digestion. Quantitation was achieved by densitometric measurement of intensity of radioactive bands corresponding to predicted size of protected probe using NIH image software. The level of CAT mRNA was expressed as relative densitometric units normalized to the level of $\beta$-gal mRNA.

Immunohistochemistry and in situ hybridization. For staining of CAT protein in transfected cells, $2 \times 10^{3}$ cells were split immediately into chamber slides after transfection and cultured for $48 \mathrm{~h}$. Cells were then fixed with ice-cold $100 \%$ methanol for $30 \mathrm{~min}$ at $-20^{\circ} \mathrm{C}$. After preincubation in blocking solution containing $10 \%$ normal goat serum and $2 \%$ albumin for $1 \mathrm{~h}$ at room temperature, slides were incubated with a polyclonal rabbit anti-CAT antibody (IgG; 5 Prime $\rightarrow 3$ Prime, Inc., Boulder, CO) at a 1:100 dilution overnight at $4^{\circ} \mathrm{C}$. Slides were then washed four times with PBS and incubated for $1 \mathrm{~h}$ at room temperature with 1:50 diluted goat anti-rabbit IgG conjugated with rhodamine. After washing the slides four times with PBS, cell nuclei were stained with $4^{\prime}$, 6-diamidino-2-phenylindole (DAPI, diluted 1:10,000). The CAT-positive cells were counted and analyzed according to morphology (stellate versus elongated). For double-staining of 
CAT and FN protein, a monoclonal mouse anti-FN IgG (Chemicon International, Inc., Temecula, CA) was also used at a 1:100 dilution, followed by probing with goat anti-rabbit IgG conjugated with Texas red, and goat anti-mouse IgG conjugated with FITC. Fluorescent labeling for tubulin and LC3 was carried out as described above using a monoclonal mouse anti-tubulin IgG (dilution 1:1,000; Sigma Chemical Co., St. Louis, MO) and a rabbit anti-LC3 antiserum (dilution 1:100; generated by J. Hammarback). Secondary antibodies used were rhodamine-conjugated goat anti-mouse or goat anti-rabbit IgG (all in dilutions of 1:100).

For colocalization of LC3 and FN mRNA, a digoxigenin-labeled FN DNA probe was generated following the manufacturer's recommendations (Boehringer Mannheim Biochemicals, Indianapolis, IN) by random priming an FN KpnI-EcoRI fragment excised from $\mathrm{pFN}$. Hybridization was performed as described previously (44). Staining of LC3 protein was then carried out with rabbit anti-LC3 antiserum as described above. Detection of digoxigenin-labeled nucleotides was accomplished by using a rhodamine-conjugated sheep anti-digoxigenin antibody (1:20 dilution; Boehringer Mannheim Biochemicals). Fluorescein-conjugated goat anti-rabbit IgG was used to detect LC3 protein. For control experiments, normal Ig was used instead of primary antibodies. Cells pretreated with RNase A $200 \mu \mathrm{g} / \mathrm{ml}$ in PBS for $1 \mathrm{~h}$ at $37^{\circ} \mathrm{C}$ were used as controls for in situ hybridization. Fluorescence microscopy was performed with an AHBT3 research photomicrographic microscope system (Olympus Optical Co., Ltd., Tokyo, Japan).

Preparation of cytoplasmic extracts and RNA gel mobility shift assays. Confluent cells were collected by scraping into 15-ml Falcon tubes (Becton Dickinson, Oxnard, CA), and spun at 2,000 rpm for 10 min. Pellets were resuspended in twice the volume of hypotonic buffer ( $25 \mathrm{mM}$ Tris-HCl, $\mathrm{pH}$ 7.9, $0.1 \mathrm{mM}$ EDTA) with proteinase inhibitors aprotinin, pepstatin, and leupeptin $(1 \mu \mathrm{g} / \mathrm{ml}$ each $)$ and lysed by three repetitive cycles of freeze-thaw. After a 1-h centrifugation at $100,000 \mathrm{~g}$ at $4^{\circ} \mathrm{C}$, the supernatants were dialyzed against RNA-binding buffer (15 mM Hepes, $\mathrm{pH} 7.9,100 \mathrm{mM} \mathrm{KCl}, 10 \%$ glycerol, 5 $\mathrm{mM} \mathrm{MgCl} 2,0.2 \mathrm{mM}$ DTT) overnight at $4^{\circ} \mathrm{C}$ and stored at $-70^{\circ} \mathrm{C}$. The concentration of protein was determined using a protein assay kit (Bio-Rad Laboratories, Richmond, CA). In a standard reaction, 40 $\mu \mathrm{g}$ of cytoplasmic extracts from DA and Ao SMC was incubated with $10^{5} \mathrm{cpm}$ of full-length $3^{\prime} \mathrm{UTR}$ probes or $10^{4} \mathrm{cpm}$ of FN RNA oligonucleotide probes in RNA-binding buffer in a total volume of $20 \mu \mathrm{l} \mathrm{con-}$ taining $2 \mu \mathrm{g}$ of tRNA for $30 \mathrm{~min}$ at $30^{\circ} \mathrm{C}$. RNase $\mathrm{T}_{1}$ was added in a concentration of $1 \mathrm{U} / \mu \mathrm{l}$, and incubation continued for $1 \mathrm{~h}$ for fulllength $3^{\prime}$ UTR probes or $10 \mathrm{~min}$ for the oligonucleotide probes before electrophoresis on a $6 \%$ native polyacrylamide gel in $0.25 \times$ TBE (Tris-borate-EDTA) buffer. For competition and specificity studies, increasing amounts of excess unlabeled RNA probe were incubated with the cytoplasmic extract for $10 \mathrm{~min}$ before adding the labeled RNA transcripts.

Ultraviolet (UV)-cross-linking assay. Cytoplasmic lysates $(40 \mu \mathrm{g})$ were incubated with the RNA oligonucleotide probe $\left(10^{5} \mathrm{cpm}\right)$ in a final volume of $20 \mu \mathrm{l}$. The binding reaction was carried out as described above. After cross-linking by $254 \mathrm{~nm}$ UV radiation (Stratalinker, one cycle of $120 \mathrm{~mJ} / \mathrm{cm}^{2}$; Stratagene Inc.), samples were boiled in 2 vol of $2 \times$ SDS sample buffer (Laemmli buffer) for $10 \mathrm{~min}$ and analyzed on $8-16 \%$ SDS-PAGE.

Purification and identification of FN $m R N A$-binding protein. The S-100 extract was prepared from the media of 21 sheep Ao (weight $98.91 \mathrm{~g}$ ). After removing the adventitia and homogenizing in buffer (10 mM Tris-HCl, pH 7.5, $100 \mathrm{mM} \mathrm{KCl,} 10 \mathrm{mM} \beta$-mercaptoethanol ( $\beta$-ME, $0.2 \mathrm{mM}$ PMSF, $0.5 \mathrm{mM}$ EDTA, and $1 \mu \mathrm{g} / \mathrm{ml}$ each of aprotinin, pepstatin, and leupeptin), the sample was centrifuged at $100,000 \mathrm{rpm}$ for $90 \mathrm{~min}$. The final volume of the S-100 extract was $220 \mathrm{ml}$, with a protein concentration of $4.3 \mathrm{mg} / \mathrm{ml}$. The extract was dialyzed extensively against column running buffer $(10 \mathrm{mM}$ Tris- $\mathrm{HCl}, \mathrm{pH} 7.5$, $10 \mathrm{mM} \mathrm{KCl}, 1 \mathrm{mM}$ EDTA, $1 \mathrm{mM} \beta-\mathrm{ME}$ ) and run through a DEAESepharose column after the column was equilibrated with running buffer. Flow-through from the DEAE-Sepharose $(250 \mathrm{ml}, 0.32 \mathrm{mg} / \mathrm{ml})$ column was loaded onto a phosphocellulose column after the column was equilibrated with running buffer. A one-step $1 \mathrm{M} \mathrm{KCl}$ eluate was collected $(130 \mathrm{ml}, 0.16 \mathrm{mg} / \mathrm{ml})$ from the phosphocellulose column. The sample was dialyzed extensively with heparin running buffer $(20 \mathrm{mM}$ Tris- $\mathrm{HCl}, \mathrm{pH} 8.0,100 \mathrm{mM} \mathrm{KCl}$ ), then loaded onto a heparin agarose column connected to a liquid chromatography apparatus (ConSep LC100; Millipore Corp., Bedford, MA) and eluted using a KCl gradient $(80-800 \mathrm{mM})$. A total of 21 fractions were collected. The protein content in the fractions was assayed using SDS-PAGE, and RNAbinding activity was determined by gel shift assays and UV-crosslinking. Fraction 19, containing a peak 15-kD RNA-binding activity (judged by UV-cross-linking), was concentrated to $20 \mu \mathrm{l}$ by ultrafiltration using Centricon-10 (Amicon Inc., Beverly, MA). The concentrated sample was resolved by SDS-PAGE. The gel was then electroblotted onto a polyvinyldifluoride (PVDF) transfer membrane, and the membrane was stained with Coomassie blue. The $15-\mathrm{kD}$ band was excised, and the sequence of the first 10 amino acids of the purified protein was determined (Biotechnology Service Center, University of Toronto, Ontario, Canada).

Western blotting. Proteins were separated by $15 \%$ SDS-PAGE and transferred onto a PVDF membrane. The blot was blocked for $1 \mathrm{~h}$ at room temperature in Tris-buffered saline (TBS) containing $0.1 \%$ Tween 20 and 5\% nonfat milk and then probed with rabbit anti-LC3 antiserum $(1: 1,000)$. The blot was washed once for 5 min with TBS containing $0.5 \%$ Tween 20 and three times for 5 min with TBS followed by incubation with horseradish peroxidase-conjugated goat anti-rabbit IgG (1:3,000; Bio-Rad Laboratories) for $1 \mathrm{~h}$ at room temperature. The blots were washed four times for 5 min with TBS and developed with $\mathrm{DAB}$ (3, $3^{\prime}$-diaminobenzidine tetrahydrochloride) in TBS containing $0.3 \% \mathrm{H}_{2} \mathrm{O}_{2}$ or with the enhanced chemiluminescence kit (ECL; Amersham Corp., Arlington Heights, IL). The intensity of immunoreactive bands was quantitated using NIH image software.

RNA extraction and northern blotting. Total RNA was extracted using TriZol solution (GIBCO BRL) following the manufacturer's instructions. $10 \mu \mathrm{g}$ of total RNA from each treatment condition was separated by $1 \%$ agarose gel, transferred onto a nylon membrane (Amersham Corp.) by capillary elution, and fixed by UV irradiation. After blocking, the membranes were probed with a $\left.{ }^{32} \mathrm{P}\right] \mathrm{dCTP}$ random-labeled 0.6-kb human FN cDNA excised from pHF at sites of KpnI-EcoRI $\left(10^{6} \mathrm{cpm} / \mathrm{ml}\right)$ overnight at $50^{\circ} \mathrm{C}$, followed by two washes with $2 \times \mathrm{SSC} / 0.1 \% \mathrm{SDS}$ at $55^{\circ} \mathrm{C}$ for $30 \mathrm{~min}$ and one wash with $0.2 \times$ $\mathrm{SSC} / 0.1 \% \mathrm{SDS}$ at $65^{\circ} \mathrm{C}$ for $1 \mathrm{~h}$. Autoradiographs of Northern blots were analyzed by quantitative densitometry. Ethidium bromide staining of $28 \mathrm{~S}$ and $18 \mathrm{~S}$ RNAs served to control for loading conditions.

Expression of recombinant LC3 and RNA binding. The LC 3 coding region was amplified by PCR using pCR $3^{\circledR}$-LC3 plasmid as a template (produced by J. Hammarback). The $5^{\prime}$ primer, $5^{\prime}$-CAGGATCCCATATGCCGTCCGAGAAGACC- $3^{\prime}$, flanked by BamHI and NdeI sites, and the $3^{\prime}$ primer, 5'-CTGGATCCGAATTCAAGCATGGCTCTCTTCC-3', flanked by BamHI and EcoRI sites, were used in the PCR. The PCR products were digested with BamHI and EcoRI and cloned into pGEX-2T (Pharmacia Biotech., Piscataway, $\mathrm{NJ})$ at the same sites. The glutathione $S$-transferase (GST)-LC3 fusion protein was purified using a glutathione-agarose column (Sigma Chemical Co.) and the recombinant LC3 was eluted from the column by adding thrombin to the column to cleave GST. The purified recombinant LC3 protein was verified by SDS-PAGE and Western blotting.

Overexpression of $L C 3$ and measurement of FN synthesis. Cultured DA and Ao SMC were transfected with pCR $3{ }^{\circledR}$-LC3 plasmid using the component system described above with reference to transfection of the CAT plasmids. Cells at passage 1 were seeded onto 12 well dishes at a density of $10^{6}$ cells/well $24 \mathrm{~h}$ before transfection and transfected with two different doses of pCR $3^{\circledR}$-LC3 $(1.67$ or $5 \mu \mathrm{g} / \mathrm{ml} /$ well). $24 \mathrm{~h}$ after transfection, cells were labeled with $\left[{ }^{35} \mathrm{~S}\right]$ methionine $(10 \mu \mathrm{Ci} / \mathrm{ml})$ and incubated for $20 \mathrm{~h}$ with medium $(2 \mathrm{ml} /$ well $)$ mixed by adding 3 vol of methionine-free DME with 1 vol of complete DME containing $20 \%$ FBS. The newly synthesized FN protein was assessed by incubating conditioned medium containing equal counts of total 
TCA-precipitated protein with $50 \mu \mathrm{l}$ of gelatin Sepharose 4B (Pharmacia Biotech). After washing with PBS, FN retained on the beads was eluted by boiling for $5 \mathrm{~min}$ in $100 \mu \mathrm{l}$ of SDS-sample buffer and resolved by $6 \%$ SDS-PAGE. Gels were treated with EN ${ }^{3}$ HANCE (DuPont-NEN, Boston, MA), dried, and exposed to the film. Using the autoradiograph as a template, the corresponding bands were cut from the gel, and the radioactivity was determined by liquid scintillation counting. Quantitative analysis of data from four different experiments was carried out using computerized SuperANOVA.

\section{Results}

The ARE in FN 3'UTR is an mRNA translational enhancer in vascular cells. Our previous studies suggested that the increased synthesis of FN in DA compared with Ao SMC is due to an increased translational efficiency of FN mRNA (6). To determine whether the FN ARE may be involved in the enhancement of FN mRNA translational efficiency in primary cultured DA versus Ao SMC, we first generated a 3'UTR regulatory CAT construct containing the CAT coding sequence, an upstream SV40 early promoter, and a downstream FN 3'UTR bearing the intact ARE, UUAUUUAU, followed by a poly(A) tail (defined as pECE-CAT-FN). Mutation was introduced into the ARE and the mutated sequence was GGAGGGAG. The mutated plasmid was defined as pECE-CAT-FN $\Delta$. The plasmid (pECE-CAT) containing CAT and its own 3'UTR was used as a control. Transfection studies were then carried out with these three constructs, and the level of CAT mRNA, as well as protein (CAT activity), were measured (see Methods).

RNase protection studies showed a significant decrease in CAT mRNA levels in both DA (50\%) and Ao SMC (38\%) transfected with pECE-CAT-FN compared with pECE-CAT after normalization with $\beta$-gal mRNA levels (Fig. $1 a$ ). This is in agreement with the level of CAT activities found in these cells (Fig. $1 b$ ), suggesting that the $3^{\prime}$ UTR of FN mRNA may decrease CAT mRNA stability relative to the native CAT 3'UTR. However, the CAT mRNA levels were similarly greatly decreased $(\sim 70 \%)$ in both DA and Ao cells transfected with pECE-CAT-FN compared with pECE-CAT-FN $\Delta$ (Fig. $1 a ; P<$ $0.05)$. This result suggests that the ARE in the $3^{\prime} \mathrm{UTR}$ of FN mRNA has mRNA-destabilizing properties, as has been described for the ARE in other mRNA species (20, 21, 23). In contrast, DA cells transfected with pECE-CAT-FN showed a 2.4-fold increase in CAT activity compared with pECE-CAT$\mathrm{FN} \Delta$ with mutated ARE $(P<0.05)$, while a relatively smaller, 1.3-fold increase was observed in Ao cells $(P<0.05)$ (Fig. $1 b)$. Table I summarizes the data illustrated in Fig. 1. Using the ratio of CAT activity to mRNA level as an index of translational efficiency, we noted that the translation of pECE-CAT-FN mRNA was more efficient than pECE-CAT-FN $\Delta$ in both DA (increased 10.9-fold) and Ao SMC (increased 6.5-fold). Thus, the ARE in the 3'UTR of FN mRNA appears to serve as an enhancer of mRNA translation, and our data are consistent with this function being amplified in DA compared with Ao cells.

Alteration of cell shape in DA SMC transfected with pECE$C A T-F N$. We established previously that the increased $\mathrm{FN}$ mRNA translation in DA compared with Ao SMC is essential for maintaining the elongated motile phenotype of these cells $(5,6)$. The transfection studies indicated that FN ARE may be responsible for this enhanced translation of FN mRNA in DA cells, and binding of cytoplasmic factors to the ARE is likely involved. As transient transfection of pECE-CAT-FN would result in abundant FN 3'UTR in transfected cells, the ARE in the fusion mRNA of pECE-CAT-FN could be expected to sequester the ARE-binding factors and reduce their binding to the ARE of endogenous FN mRNA, thereby decreasing the expression of FN protein in those cells and altering the FNdependent elongated migratory cell shape. To determine whether this does, in fact, occur, we examined CAT-positive cells by immunostaining and correlated the cell shape and the expression of FN with transfected plasmids. Fig. $2 a$ shows that of a total number of CAT-positive cells transfected with control plasmid pECE-CAT (mean $=25$, range 19-30), $82 \%$ (range $=72-89 \%$ ) had an elongated phenotype. However, in CAT-positive cells transfected with wild-type plasmid pECECAT-FN (mean $=21$, range 15-30), only 54\% (range 47$60 \%$ ) showed the elongated phenotype. In CAT-positive cells transfected with mutated plasmid pECE-CAT-FN $\Delta$ (mean $=$ 18 , range $16-20), 77 \%$ (75-80\%) were elongated. The decrease in the percentage of elongated cells after transfection with pECE-CAT-FN was significant $(P<0.05)$. Fig. $2 b$ is a representative photograph of cells from these experiments.

Since transient transfection using the calcium phosphate method had only a $1-2 \%$ transfection efficiency, and cells were cultured at low density to visualize cell morphology, it was difficult to assess FN production. To overcome this limitation, we used a more efficient method of adenovirus transfection described in Methods. This system had been shown to allow $>70 \%$ of primary cultured cardiac cells to express transfected genes (43). We applied double-immunofluorescence using both

Table I. Measurements of CAT Activity, $m R N A$, and Ratio of CAT Activity to $m R N A$

\begin{tabular}{lccr}
\hline \multicolumn{1}{c}{ Transfectant } & CAT activity & CAT mRNA & CAT activity/mRNA \\
\hline & $n=6$ & $n=3$ & 13.800 \\
DA/pECE-CAT & $30.678 \pm 4.396$ & $2.223 \pm 0.075$ & 17.253 \\
DA/pECE-CAT-FN & $19.272 \pm 4.622^{*}$ & $1.117 \pm 0.074^{*}$ & 1.450 \\
DA/pECE-CAT-FN $\Delta$ & $5.745 \pm 0.847$ & $3.963 \pm 0.154$ & 10.016 \\
Ao/pECE-CAT & $18.330 \pm 2.218$ & $1.830 \pm 0.190$ & 9.692 \\
Ao/pECE-CAT-FN & $11.078 \pm 1.923^{*}$ & $1.143 \pm 0.046^{*}$ & 1.299 \\
Ao/pECE-CAT-FN $\Delta$ & $4.915 \pm 0.523$ & $3.783 \pm 0.202$ & \\
& & & \\
\hline
\end{tabular}

Values are mean \pm SEM. $\mathrm{n}$, Number of experiments. ${ }^{*} P<0.05$, compared with the group above and below by SuperANOVA and Duncan's new multiple range test. 

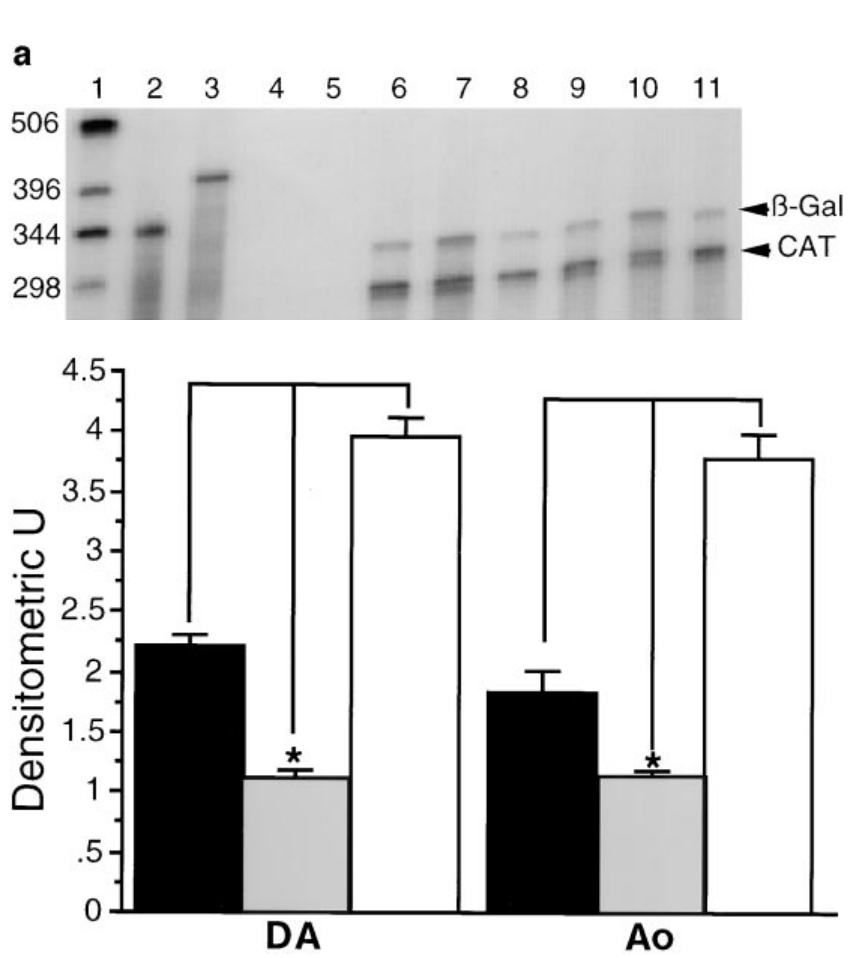

DA
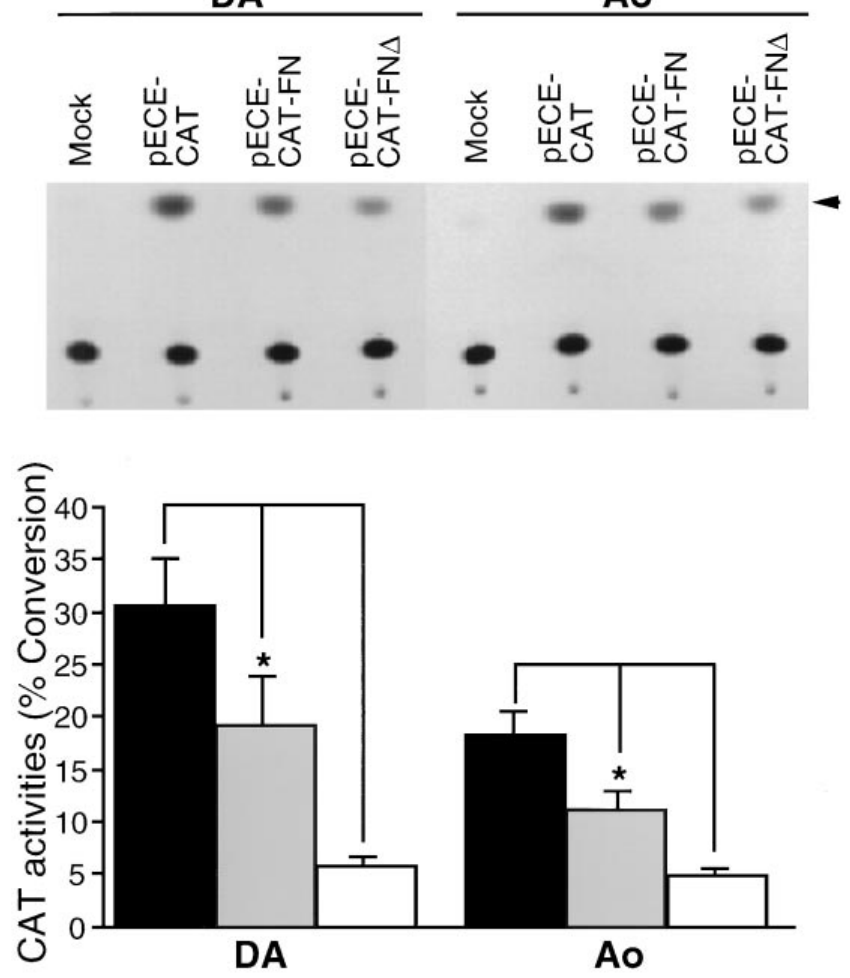

Figure 1. The ARE in the 3'UTR of FN mRNA enhances translation. (a) Top, Representative autoradiograph of RNase protection assay. Bottom, Densitometric analysis of three different experiments. Lane 1, A 1-kb DNA ladder as a marker. Lanes 2 and 3, Only the full-length CAT (325 bp) and $\beta$-gal (378 bp) probes, respectively. Lanes 4 and 5, Negative controls using CAT and $\beta$-gal probes to hybridize with yeast RNA, respectively, showing no protected RNA fragment. Lanes 6-8, RNA from DA SMC; lanes 9-11, RNA from Ao SMC transfected with different CAT constructs (lanes 6 and 9 , pECE-CAT; lanes 7 and 10, pECE-CAT-FN; lanes 8 and 11 pECE-CAT-FN $\Delta$ ) hybridized with CAT as well as $\beta$-gal probes. The protected CAT (260 bp) and $\beta$-gal (289 bp) probes are indicated (arrows, right; an RNA fragment will run slightly slower than a DNA fragment of the same size). Bottom, Densitometric studies show a significant decrease in the level of CAT mRNA in both DA (50\%) and Ao SMC (38\%) transfected with pECE-CAT-FN (gray bars) compared with pECE-CAT (black bars), which is consistent with the decreases in CAT activities. However, when compared with cells transfected with pECE-CAT-FN $\Delta$ (white bars), a remarkable decrease in the CAT mRNA level is found in both DA (72\%) and Ao SMC (70\%) which is not associated with decreased but rather with increased CAT activities. The CAT mRNA level was normalized with $\beta$-gal mRNA, which was used to control for transfection efficiency and loading conditions. $* P<0.05$. (b) Top, Representative autoradiograph of CAT assays. Bottom, Quantitative results of CAT assays from six separate transfection studies using control plasmid (pECE-CAT, black bars), plasmid containing wild-type ARE (pECE-CAT-FN, gray bars), and plasmid containing mutated ARE (pECE-CAT-FN $\Delta$, white bars). Mock-transfected cells show radiolabeled nonacetylated chloramphenicol only, whereas the acetylated product is observed in cells transfected with CAT constructs (arrow). The CAT activity is decreased significantly in either DA (37\%) or Ao cells (40\%) transfected with the plasmid pECE-CAT-FN compared with pECE-CAT $(* P<0.05)$. However, there is a significant increase in CAT activity in both DA (2.4-fold) and Ao cells (1.3-fold) transfected with pECE-CAT-FN compared with pECE-CAT-FN $\Delta\left({ }^{*} P<0.05\right)$, suggesting that the FN ARE is also functionally involved in mRNA translation.

a Texas red-tagged antibody to visualize CAT expression (Fig. $2 c, A, C$, and $E$ ), and an FITC-conjugated antibody to examine FN expression $(B, D$, and $F)$. While almost all the cells transfected with CAT constructs showed positive staining for CAT, we observed a consistent decrease in the accumulation of $\mathrm{FN}$ in the cell cultures transfected with pECE-CAT-FN (Fig. $2 C, D$ ) compared with pECE-CAT $(B)$ or pECE-CAT$\mathrm{FN} \Delta(F)$, which also correlated with a more stellate compared with elongated phenotype. The negative controls using normal IgG showed that almost all of the fluorescence signal was abolished (Fig. $2 C, G$ ). Thus, the sequestration of cytoplasmic factors by the ARE in pECE-CAT-FN may underlie the decrease in FN production as well as the cell shape change.

Identifying FN ARE-binding activity. Studies were next undertaken to identify a cytoplasmic factor with FN $3^{\prime}$ UTR
ARE-binding properties. Gel mobility shift assays were carried out in which S-100 cytoplasmic extracts prepared from cultured DA or Ao SMC were incubated with a ${ }^{32} \mathrm{P}$-labeled full-length FN 3'UTR with intact or mutated ARE. While probe alone showed no binding complex formation (Fig. $3 a$, lanes 1 and 3), three retarded bands were found in DA S-100 extracts with wild-type FN 3'UTR probe (lane 2). However, the major retarded band was not observed when using the ARE-mutated probe (Fig. $3 a$, lane 4). This indicated that there are cytoplasmic factors that could bind to FN $3^{\prime} \mathrm{UTR}$, and that at least one of these RNA-cytoplasmic factor interactions is related to the ARE. The specificity of this interaction was also assessed by the competition experiments using an ARE-containing FN oligonucleotide probe, as well as an irrelevant probe (without ARE) of the same size. Two binding 


\section{b}
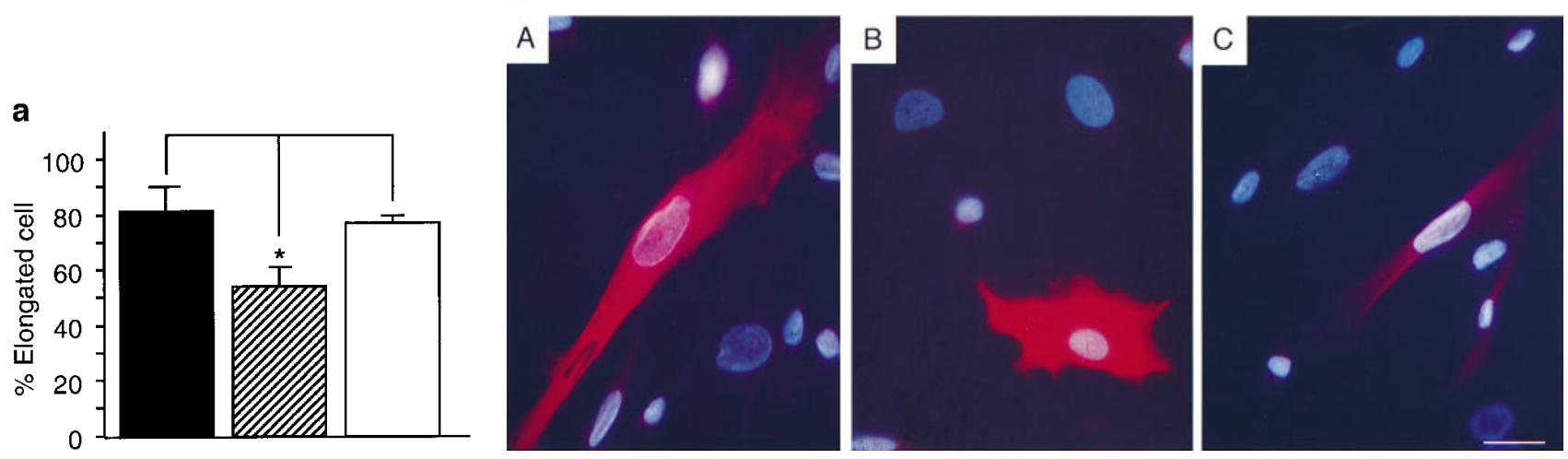

c
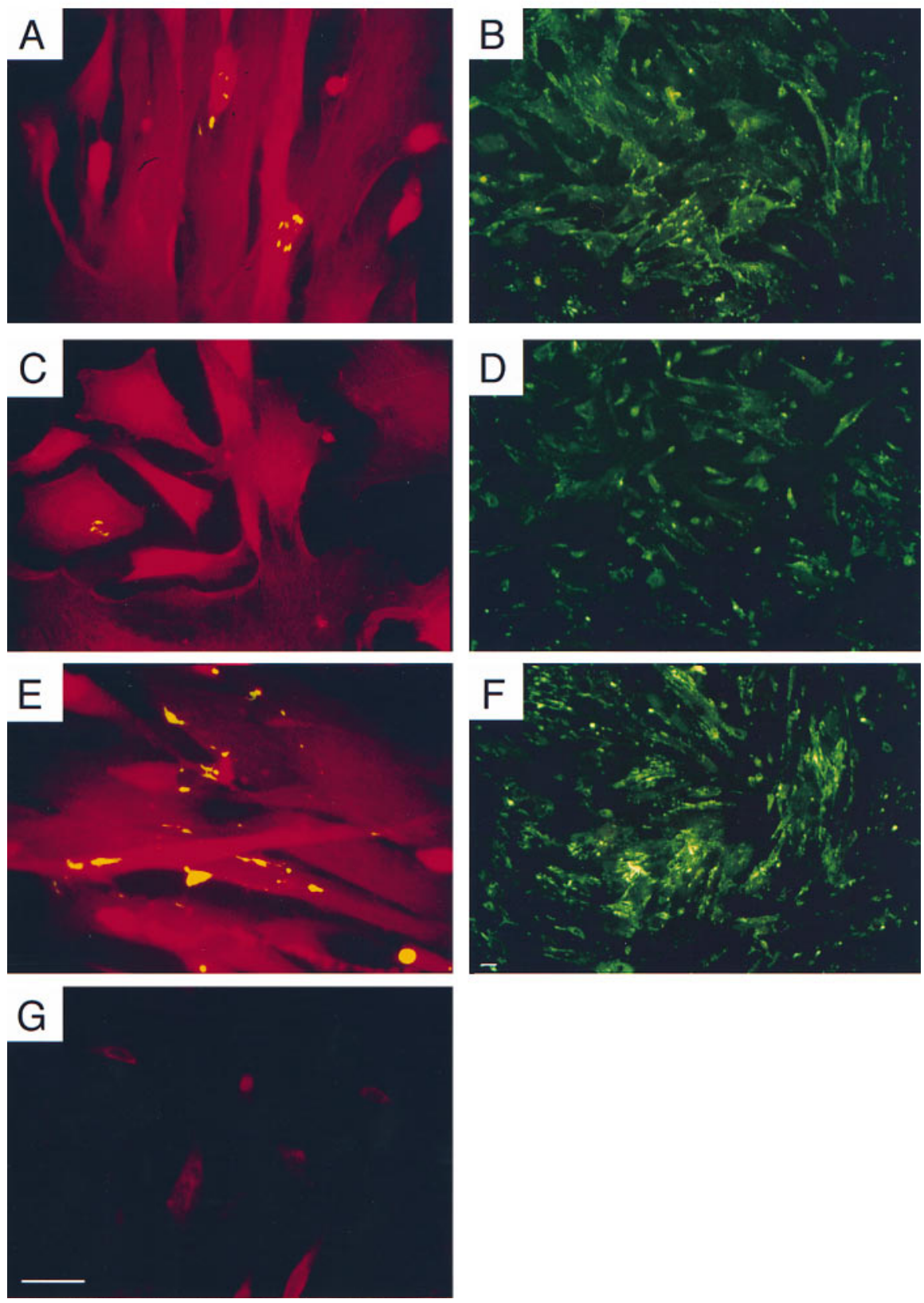

Figure 2. Overexpression of pECE-CAT-FN altered cell phenotype and decreased FN. (a) Summarizes the quantitative analysis of the change of cell shape in CAT-positive cells from three different experiments. Mean percentage of cells with elongated shape \pm SEM. *Significant difference, $P<0.05$, by SuperANOVA and Duncan's multiple range test. As seen in the graph, the percentage of cells with elongated shape is reduced significantly in cells transfected with pECE-CAT-FN (striated bars) compared with cells transfected with pECE-CAT (black bars) and pECE-CAT-FN $\Delta$ (white bars). (b) Representative photomicrograph showing cells transfected with control plasmid pECE-CAT $(A)$, ARE-containing plasmid pECE-CATFN $(B)$, or ARE-mutated plasmid pECECAT-FN $\Delta(C)$ using the calcium phosphate method (see Methods). Cells were stained for CAT with rhodamine-conjugated secondary antibody, and nuclei were stained with DAPI. Compared with pECE-CAT $(A)$ or pECE-CAT-FN $\Delta(C)$, overexpression of pECE-CAT-FN altered cell shape from elongated to stellate. (c) Representative simultaneous immunofluorescence staining of $\mathrm{CAT}(A, C$, and $E)$ and $\mathrm{FN}$ protein $(B, D$ and $F$ ) in transfection studies using a component adenovirus delivery system (see Methods). Almost all the cells stain positive for CAT by Texas red-conjugated secondary antibody. The staining for FN reveals cell surface matrix deposits by FITC-conjugated secondary antibody. The staining for FN is less intense in cells transfected with pECECAT-FN $(D)$ compared with either control plasmid pECE-CAT $(B)$ or ARE-mutated plasmid pECE-CAT-FN $\Delta(F)$. $G$ is a negative control, with normal IgG. Bar $=10 \mu \mathrm{m}$. 
complexes were observed on gel shift using the specific AREcontaining probe (SP) (Fig. $3 b$, lane 2; lane 1 containing probe only as a control). They may represent the same binding factor with different degrees of aggregation or different binding factors. No binding complex formation was found with the irrele-
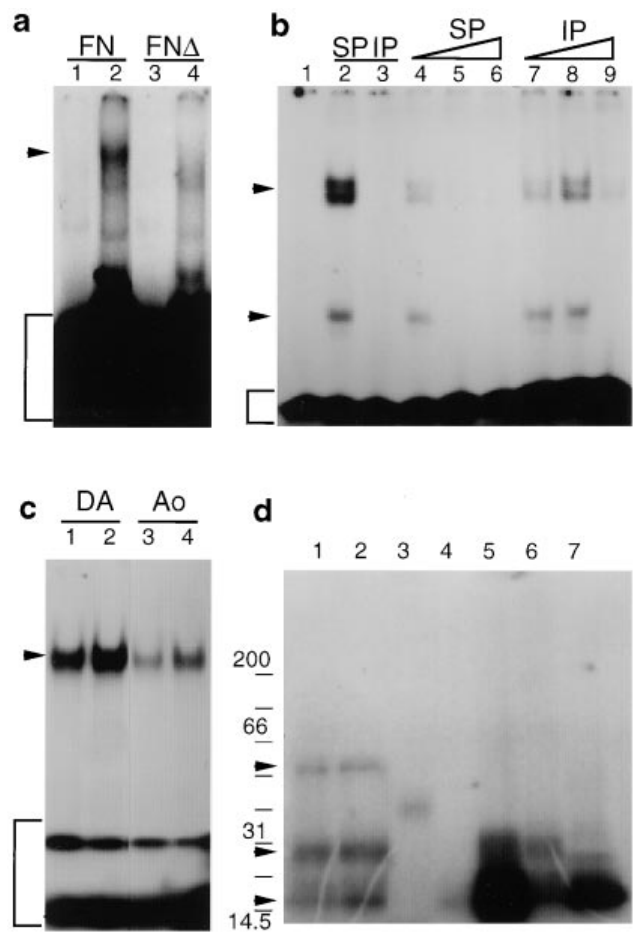

Figure 3. Formation of a binding complex between the FN ARE and SMC cytoplasmic factors. (a) Representative autoradiograph of a gel shift assay using DA SMC S-100 cytoplasmic extracts and radiolabeled full-length FN 3'UTR containing wild-type ( $F N$; lane 2$)$ or mutated ARE ( $F N \Delta$; lane 4$)$. Lanes 1 and 3 are controls without S-100 extracts. Arrow shows that the binding complex is specifically related to wild-type FN 3'UTR (compare lane 2 with lane 4). Bracket, Free probe. (b) Gel shift assay with the oligonucleotide containing the ARE $(S P)$ or irrelevant probe. Lane 1, radiolabeled probe alone; lane 2, SP + S-100 extracts, showing two binding complexes (arrows) lane 3, IP + S-100 extracts, showing no binding complex formation. Preincubation of an increased amount of unlabeled SP (10-, 50-, and 200-fold, lanes 4-6) with S-100 extracts prevented binding complex formation in a dose-dependent manner, but not IP with the same order of concentrations (lanes 7-9). (c) Gel shift assay using S-100 extracts from cultured DA (lanes 1 and 2) and Ao SMC (lanes 3 and 4) under serum-free conditions (lanes 1 and 3 ) or following serum-stimulation (lanes 2 and 4). Compared with Ao S-100 extracts, an increased binding complex formation is evident with DA S-100 extracts in both serum-free and serum-stimulation conditions. (d) UV-crosslinking assay of the cytoplasmic factors with radiolabeled FN AREcontaining oligonucleotide. Lane 1 , binding complexes run under nonreducing conditions. Lane 2 , binding complexes run under reducing conditions. Lane 3, S-100 extracts incubated with $1 \mu \mathrm{g} / \mu \mathrm{l}$ proteinase $\mathrm{K}$ for $30 \mathrm{~min}$ at $37^{\circ} \mathrm{C}$ before the binding reaction. Lane 4 , the oligonucleotide probe was treated with $1 \mathrm{U} / \mu \mathrm{l}$ RNase $\mathrm{T}_{1}$ before incubation with the S-100 extracts. Lanes 5-7, S-100 extracts were pretreated with $2 \% \beta$-ME, $10 \mathrm{mM}$ DTT, or $10 \mathrm{mM} N$-EM, respectively, for $30 \mathrm{~min}$ at $37^{\circ} \mathrm{C}$ before incubation with the oligonucleotide. Protein molecular mass markers are indicated (left). The relative molecular masses of the binding complexes were estimated at $\sim 60,000,30,000$, and $15,000-\mathrm{kD}$ (arrows). vant probe (IP) (Fig. $3 b$, lane 3). Preincubation of unlabeled SP (10-, 50-, and 200-fold of radiolabeled SP) with S-100 extracts shows dose-dependent inhibition of radiolabeled SP binding (Fig. $3 b$, lanes 4-6), but the unlabeled IP was inefficient in blocking radiolabeled SP binding (lanes 7-9).

Further gel shift assays revealed formation of a similar binding complex between ARE-containing oligonucleotides and S-100 extracts from both DA and Ao SMC (Fig. $3 c$, lanes 1 and 3). However, there was a consistent increase in the intensity of binding complex formation with DA compared with Ao cytosols, especially after serum stimulation (Fig. $3 c$, lane 2 vs. lane 4). The binding was dose-dependent, since increased binding complex formation correlated with increased amounts of S-100 extracts used in the binding reaction (data not shown). Thus, the increased binding complex formation in DA S-100 extracts may reflect an increased amount of ARE-binding factors in DA compared with Ao cells. To determine the conditions under which binding might occur, we studied the kinetics of formation of the binding complex. Binding reactions were carried out for various times before termination by the addition of RNase $T_{1}$. Incubations as short as 5 min yielded similar amounts of binding complex as a 1-h incubation (data not shown), as has been described for AUBFs (31).

Additional studies were carried out to determine whether the binding complex consists of several subunits, and whether the binding requires free sulfhydryl groups, as suggested for the iron response element-binding protein (7) or the AUBF (45). In two different experiments, we treated the cytoplasmic extracts with reducing reagents $\beta-\mathrm{ME}$ or DTT, or the alkylating reagent $N$-ethylmaleimide $(N$-EM), before the binding reaction. The binding complexes were then UV-cross-linked and resolved by $8-16 \%$ SDS-PAGE. In the absence of pretreatment with reducing or alkylating agents, three radioactive bands migrated at positions related to $\sim 60,000,30,000$, and $15,000 M_{\mathrm{r}}$ (Fig. $3 d$, lanes 1 and 2; gel run under nonreducing and reducing conditions, respectively). To confirm that the components of the binding complex were proteins and RNA, cytoplasmic extracts were treated with proteinase $\mathrm{K}$ or the radiolabeled probes were pretreated with RNase $\mathrm{T}_{1}$ before the binding reaction (Fig. $3 d$, lanes 3 and 4, respectively). Both conditions prevented the binding complex formation observed originally, confirming a protein-RNA interaction. The weak $40-\mathrm{kD}$ band could be attributed to incomplete digestion with proteinase $\mathrm{K}$.

However, of particular interest was the observation that the binding complex was resolved as a major intense band at $15-\mathrm{kD}$ after pretreatment of the extracts with reducing reagents $\beta$-ME (Fig. $3 d$, lane 5 ) or DTT (lane 6), as well as with the alkylating reagent $N$-EM (lane 7). The relative differences observed in the intensity of the $15-\mathrm{kD}$ band may be related to differences in reducing capacity of $\beta-\mathrm{ME}$ and DTT in the doses used. Both reducing and alkylating conditions prevent disulfide bond formation. Since $N$-EM also alkylates irreversibly reduced sulfhydryl groups, and pretreatment of cytoplasmic extracts with $N$-EM did not inhibit the $15-\mathrm{kD}$ binding complex formation, free sulfhydryl groups seem not to be required for direct binding of the $\sim 15-\mathrm{kD}$ protein to RNA. Thus, the higher relative molecular mass binding complexes may be due to disulfide bond-dependent interaction between multimers of the $\sim 15-\mathrm{kD}$ protein, or between the $15-\mathrm{kD}$ protein and other proteins, or disulfide bond-dependent RNA binding of two different $\sim 30,000$ - and $60,000-M_{\mathrm{r}}$ proteins. 
Purification and identification of the 15-kD FN ARE-binding protein. The aim of the purification procedure was to identify the nature of the $15-\mathrm{kD}$ ARE-binding protein. We designed a large-scale purification scheme based on sequential ion-exchange and heparin chromatography (Fig. 4). Gel shift and UV-cross-linking assays were used to detect RNA-binding activity and to monitor the purification process. Most of the FN mRNA-binding activity in the S-100 extract from sheep Ao tissues was resolved initially as a slow migrating band on gel shift assay (Fig. $5 a$, lane 1 ) and an $\sim 60-\mathrm{kD}$ band on UVcross-linking assay (Fig. $5 b$, lane 1 ). A weak $\sim 50-\mathrm{kD}$ band was present inconsistently. It was conceivable that the majority of $\sim 15-\mathrm{kD}$ binding protein in the S-100 extract was present as a protein complex due to the high protein concentration of the starting material. This could explain why two separate RNAbinding complexes were found subsequently on gel shift using the flow-through fraction from the DEAE-Sepharose column (Fig. $5 a$, lane 2 ) as well as on UV-cross-linking assay $(\sim 15$ and $30 \mathrm{kD}$; Fig. $5 \mathrm{~b}$, lane 2 ), while the $60-\mathrm{kD}$ binding activity remained bound (data not shown). Interaction with the DEAE column appeared to dissociate the high molecular mass binding complex, as well as separate the high and low molecular mass binding activities.

The flow-through fraction of the DEAE column containing the 15 and $30-\mathrm{kD}$ RNA-binding activities was loaded onto the phosphocellulose column (second column), and the bound material was eluted by $1 \mathrm{M} \mathrm{KCl}$. The eluate containing the 15-, as well as 30-kD RNA-binding activities (Fig. 5, $a$ and $b$, lane 3) was further purified by heparin chromatography. 21 fractions were eluted using an $80-800 \mathrm{mM} \mathrm{KCl}$ gradient. Aliquots of fractions 7-21 were tested by gel shift (Fig. 5a, lanes 4-18) and UV-cross-linking assay (Fig. $5 b$, lanes 4-18). The SDS-PAGE gels of the UV-cross-linking assay were also stained by Coomassie blue (Fig. 5 c). Fractions 17-20 (Fig. 5, $a$ and $b$, lanes 14-17) contained the majority of the binding activity, evident as a smear between 30 and $40 \mathrm{kD}$ and a clearly resolved radioactive band at $\sim 15 \mathrm{kD}$. In fraction 20 , weak $\sim 21-\mathrm{kD}$ binding activity was also observed (Fig. $5 b$, lane 17). On Coomassie blue staining, a $15-\mathrm{kD}$ protein was evident corresponding to the $\sim 15-\mathrm{kD}$ complex (compare Fig. $5 c$ to Fig. $5 b$, lanes 14

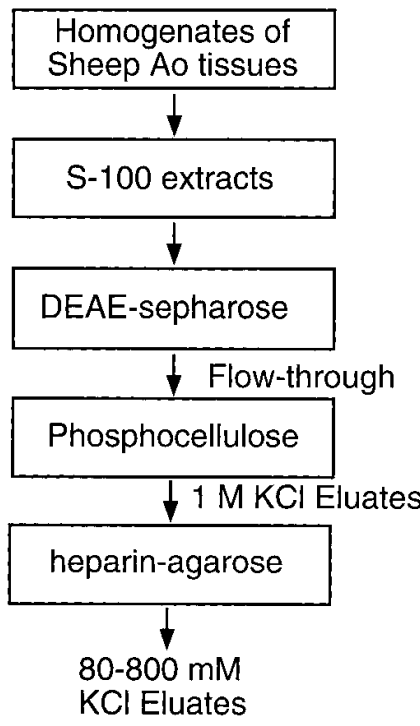

Figure 4. Diagram of the purification procedure. Gel shift and UV-cross-linking assays were applied to monitor the purification procedure and determine the ARE-binding activities in samples collected from each purification step.
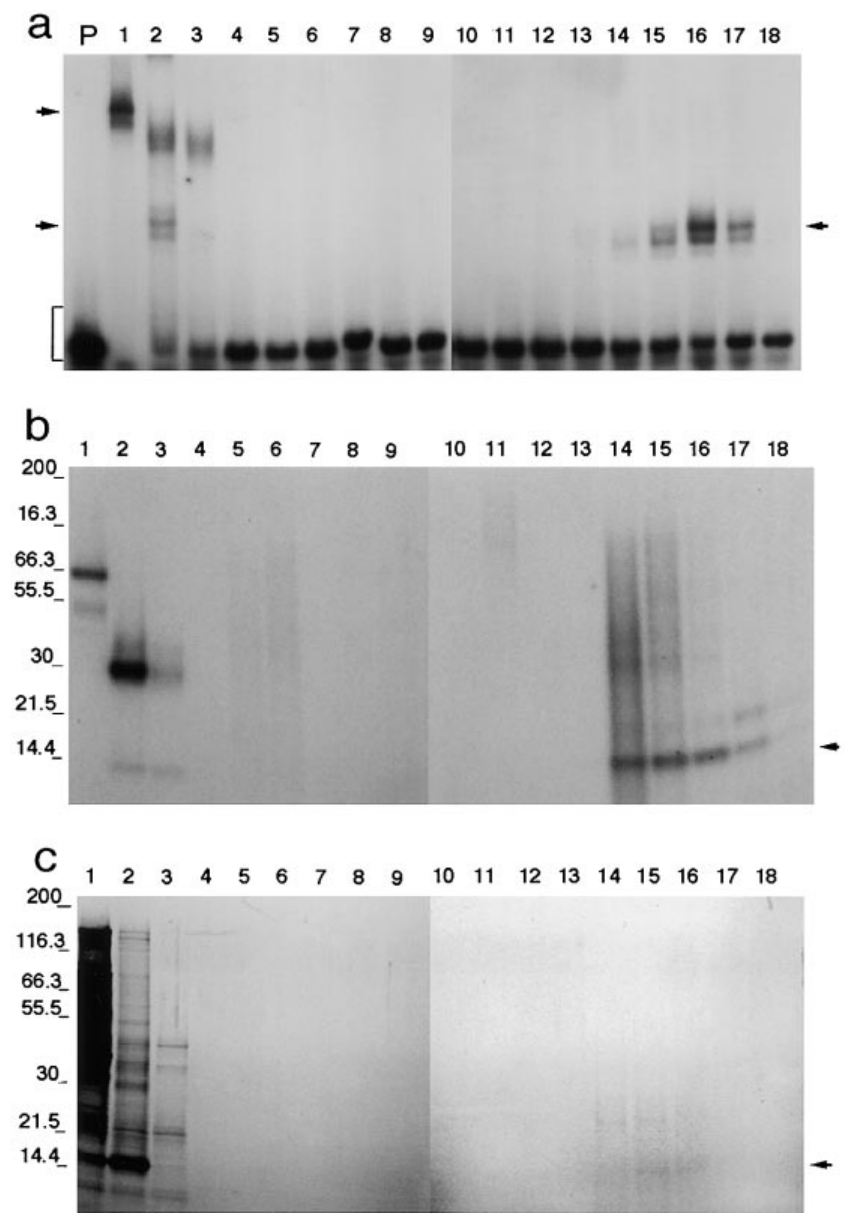

Figure 5. Purification of FN ARE-binding protein. The purification procedure was monitored by gel shift $(a)$ and UV-cross-linking assays $(b)$ using ARE-containing FN oligonucleotide probes. The protein contents in each sample were stained by Coomassie blue (c). $P$, Probe only as control. Bracket, Free probe. ARE-binding activities in S-100 extracts were revealed on gel shift as a major binding complex ( $a$, lane 1 ) and $\sim 60$-kD radioactive band on UV-cross-linking ( $b$, lane 1). Lane 1 in $c$ shows dense protein staining of S-100 extracts. The binding activities were present in the DEAE-unbound materials as two separate binding complexes indicated by gel shift ( $a$, lane 2 ) of $\sim 15,000$ and 30,000 $M_{\mathrm{r}}$ on UV-cross-linking and SDS-PAGE $(b$, lane 2). The DEAE flow-through was loaded onto the phosphocellulose column, and $1 \mathrm{M} \mathrm{KCl}$ eluates containing RNA-binding activities were collected ( $a$ and $b$, lane 3 ). The eluates of the phosphocellulose column were further applied to a heparin chromatography and eluted with an 80-800 mM KCl gradient, and 21 fractions were collected. Aliquots of fractions 7-21 were tested by gel shift ( $a$, lanes 4-18) and UV-cross-linking assay ( $b$, lanes 4-18) and stained with Coomassie blue (c, lanes 4-18). Only fractions 17-20 ( $a$, lanes 14-17) contained detectable binding activity at $\sim 15 \mathrm{kD}(b$, lanes $14-17)$ which corresponded with protein staining (c, lanes 14-17). Arrow, Binding complexes or $\sim 15$-kD protein band.

17). The peak $\sim 15-\mathrm{kD}$ binding activity corresponded to fraction 19 (Fig. $5 a$, lane 16), which was eluted at a salt concentration of $\sim 700 \mathrm{mM}$.

Fraction 19 was concentrated, separated by $15 \%$ SDSPAGE, and blotted onto a PVDF membrane. The 15-kD Coomassie blue-staining band was excised (Fig. $6 a$ ). The sequence 
of the first 10 amino acids of this purified protein was determined as PSEKTFKQRR. A GenBank database search revealed that the sequence is $100 \%$ homologous to rat MAP1 LC3, an $\sim 16-\mathrm{kD}$ protein found previously to be expressed predominantly in brain and to a lesser extent in testis (37). Western immunoblot analysis was carried out using rabbit anti-LC3 antiserum to corroborate the identity of the purified $15-\mathrm{kD}$ FN mRNA-binding protein as LC3, and to examine its expression in DA versus Ao SMC. The purified $15-\mathrm{kD}$ protein in fraction 19 is immunoreactive with the LC3 antibody, as expected (Fig. 6 b). Moreover, the protein in DA or Ao S-100 extracts that reacted with the LC3 antibody is $15 \mathrm{kD}$. Also noted is that DA S-100 cytoplasmic extracts contain more than twice the amount of LC3 compared with Ao extracts. These findings are consistent with the results of the gel shift assays showing more FN mRNA-binding complex formation with DA compared with Ao SMC S-100 extracts (Fig. $3 c$ ).

Binding of recombinant LC 3 to FN ARE. To examine the RNA-binding activity of LC3, we expressed rat LC3 in Escherichia coli as a GST-LC3 fusion protein. The purified recombinant LC3 protein was verified by SDS-PAGE, Coomassie blue staining (Fig. $7 a$ ), and Western immunoblotting (Fig. $7 b$ ). We then used the gel mobility shift assay to examine the binding activity of recombinant LC3 to the FN mRNA 3'UTR (Fig. $7 c$ ). Three retarded binding complexes were found on the gel, the formation of which was not evident using the ARE-mutated FN 3'UTR probe. This study indicated that the RNA-LC3 interaction was ARE-dependent, and that the three binding complexes may represent interaction of RNA with different aggregates of LC3. The specificity of ARE-binding of LC3 was further determined by competition assays using unlabeled ARE-mutated or ARE-containing oligonucleotides (Fig. $7 d$ ). Incubation of ARE-mutated oligonucleotides with LC3 (molar ratio 100:1) before adding radiolabeled FN 3'UTR was inefficient in blocking the formation of LC3-RNA complexes.

a

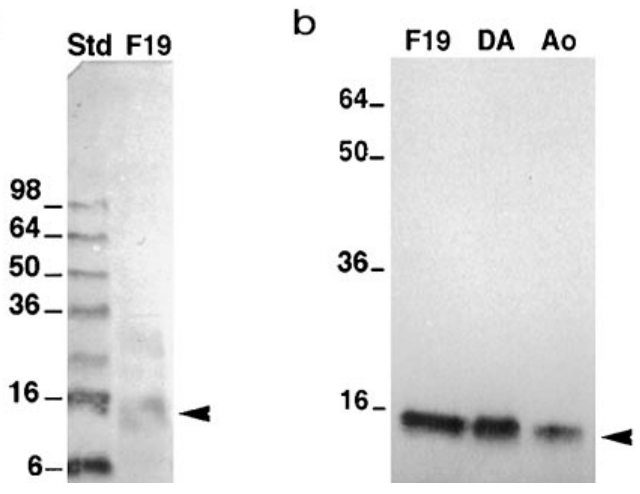

Figure 6. Identification of $15-\mathrm{kD}$ FN ARE-binding protein. (a) Coomassie blue staining of a PVDF membrane. Fraction 19 (F19) containing the peak $\sim 15-\mathrm{kD}$ RNA-binding activity (see lane 16 in Fig. 5) was concentrated, separated by SDS-PAGE, and electroblotted onto a PVDF membrane. The $\sim 15-\mathrm{kD}$ protein band (arrow) stained with Coomassie blue was excised, and the sequence of the first 10 amino acids was determined. The sequence is PSEKTFKQRR, which is $100 \%$ homologous to rat MAP1 LC3. (b) Western blot analysis using rabbit anti-LC3 antibody corroborates the purified FN mRNA-binding protein as LC3 and examines its levels in DA versus Ao SMC S-100 extracts.

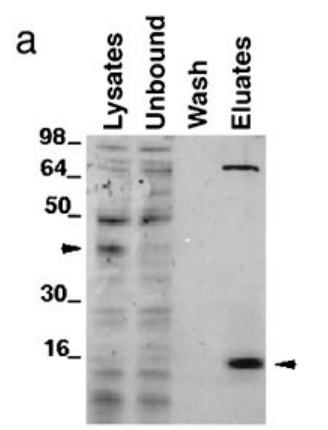

b
C

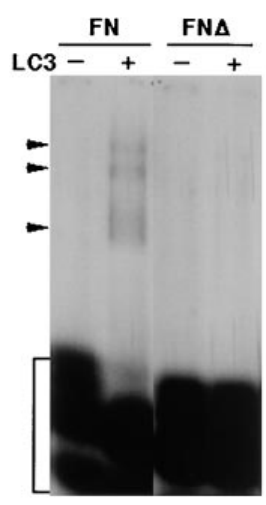

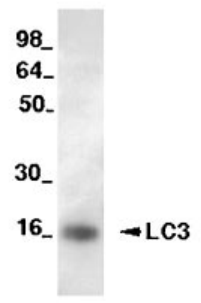

d

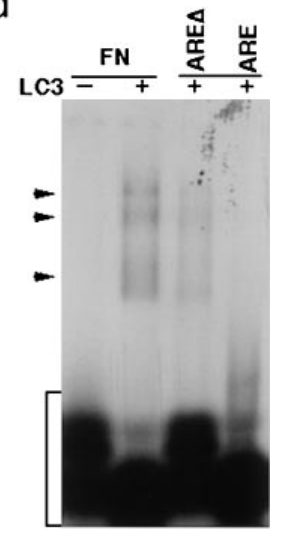

Figure 7. Recombinant LC3 binds to the ARE in the $3^{\prime} \mathrm{UTR}$ of FN mRNA. (a) Coomassie blue-stained gel showing purified recombinant LC3. Arrows, GST-LC3 fusion protein $(\sim 44 \mathrm{kD})$ in the bacterial lysates and the recombinant LC3 $(\sim 15 \mathrm{kD})$ in the eluates after cleavage of the GST tag (see Methods). The high molecular mass band $(\sim 70 \mathrm{kD})$ may be related to a protein product of the E. coli gene dnaK, which is involved in the degradation of abnormal protein in E. coli. (b) Western blot demonstrates that the recombinant LC3 reacts to anti-LC3 antibody. (c) Recombinant LC3 binds to FN 3'UTR with wild-type ARE $(F N)$ but not to FN 3'UTR with mutated ARE $(F N \Delta)$ on gel shift assay. Three binding complexes were found (arrows). The binding reactions were carried out with $0.1 \mu \mathrm{g}$ purified recombinant $\mathrm{LC} 3$ protein and $10^{5} \mathrm{cpm}$ of radiolabeled FN $3^{\prime} \mathrm{UTR}$ with intact $(F N)$ or mutated ARE $(F N \Delta)$. (d) Competition study with ARE-containing FN oligonucleotides $(A R E)$ or ARE-mutated oligonucleotides ( $A R E \Delta$; all the U's in ARE were replaced by G's). The unlabeled oligonucleotides were preincubated with LC3 at molar ratio 100:1 for $10 \mathrm{~min}$ before addition of radiolabeled FN ARE-containing oligonucleotide $\left(10^{5} \mathrm{cpm}\right)$.

However, preincubation of ARE-containing oligonucleotides with LC3 abolished completely the binding complex formation.

Distribution of LC3 and FN mRNA in cultured SMC. Since LC3 binds tubulin directly in an in vitro microtubule assembly assay with purified rat brain tubulin, and colocalizes with MAP1B in cultured rat neurons (37), immunofluorescent staining was performed to study the intracellular distribution of LC3 and FN mRNA in cultured SMC. Staining for microtubules with anti- $\alpha$-tubulin antibodies was also carried out to exclude artifacts due to the effects of fixation and staining on microtubule structure. In cells showing well-maintained microtubule structures (Fig. $8 a, B$ ), punctate immunostaining for LC3 was evident especially in the perinuclear area, but extend- 
ing throughout the cytoplasm $(A)$. Negative controls using normal IgG showed no immunofluorescence (Fig. $8 a, C$ and $D)$. In the simultaneous immunostaining of LC3 protein and FN mRNA (Fig. $8 b)$, both LC3 ( $A$; FITC) and FN mRNA $(B$; rhodamine) were observed in greatest density in the perinuclear region where colocalization was most prominent, with less intense staining apparent toward the leading edges of the cell $(C)$. Negative controls using normal $\mathrm{IgG}$ and cells pretreated with RNase A showed no immunofluorescence (Fig. $8 b, D$ ).

Overexpression of LC3 in Ao cells enhances FN $m R N A$ translation. To define the role of LC3 in the regulation of FN mRNA translation, we used adenovirus transfection to overexpress this protein in cultured DA and Ao SMC. Transfection with LC3 plasmid in Ao cells increased LC3 production (Fig. 9 $a$, top) and FN synthesis (Fig. $9 a$, bottom, and Fig. $9 b$ ) in a dose-dependent manner to the level seen in the control DA cells. However, transfection of DA cells with increasing doses of LC3 plasmid did not result in a further increase in FN synthesis, suggesting that the mechanism may be operating at maximum efficiency. Since there was no change in FN mRNA levels after LC3 transfection in either DA or Ao cells (Fig. 9 c), the results support the role of LC3 in enhanced translation of FN mRNA.

\section{Discussion}

Our study was directed at identifying the molecular mechanism underlying the developmental program that regulates SMC motility by enhanced FN mRNA translation. To this end, a
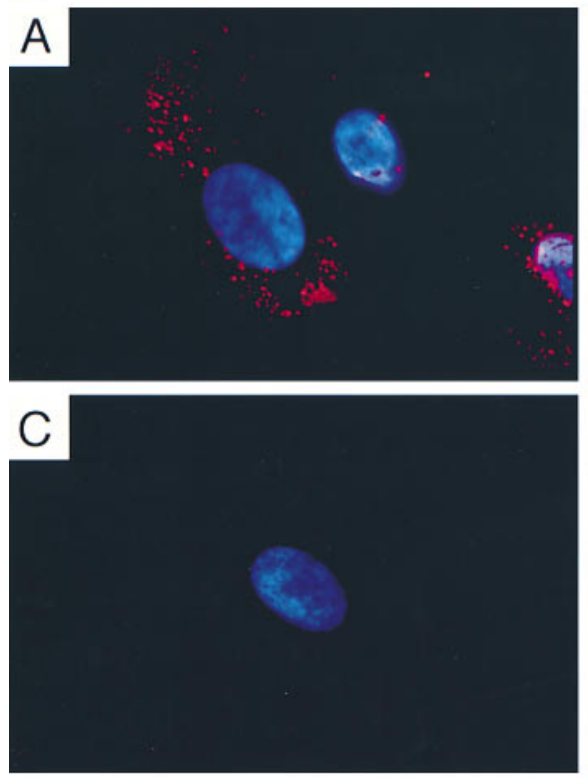

b
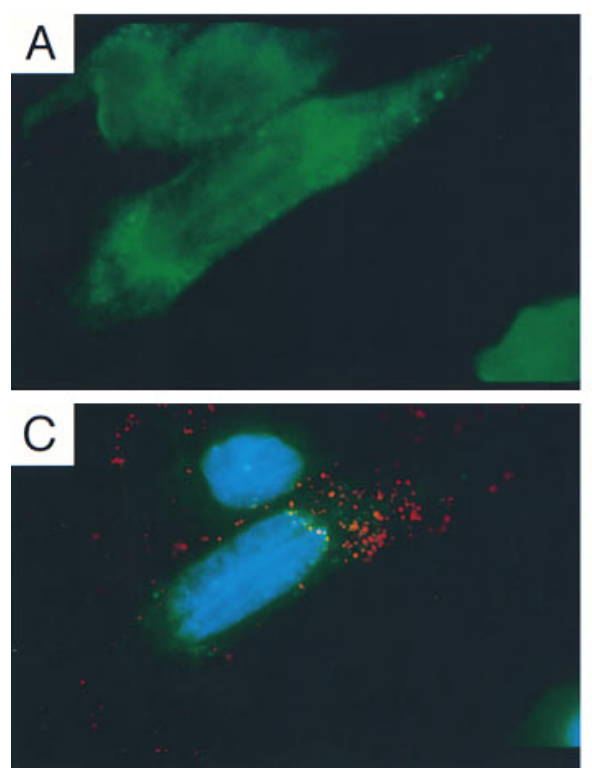
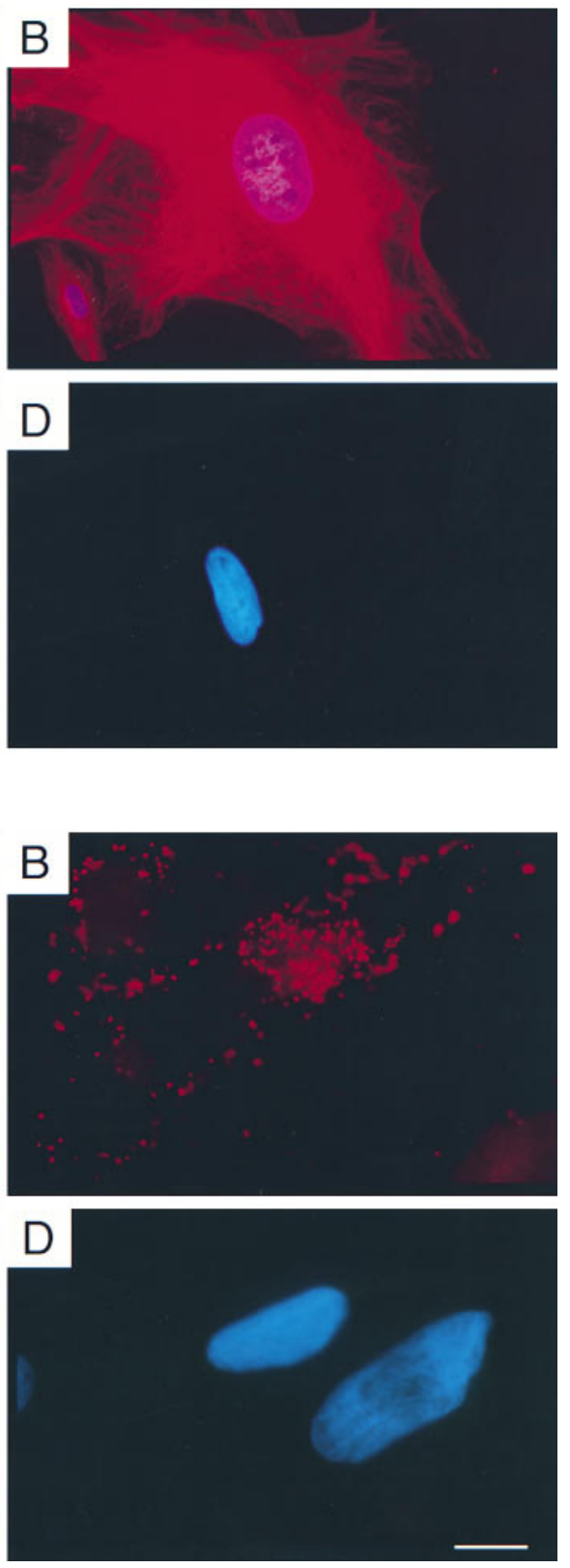

Figure 8. Codistribution of LC3 with FN mRNA in cultured cells. (a) Immunofluorescent staining of LC3 $(A)$ and tubulin $(B)$ using rhodamine-conjugated secondary antibodies in cultured DA SMC in the same set of experiments. The LC3 is observed in the perinuclear region as punctate staining $(A)$ in cells with well-preserved microtubules $(B)$. Controls for LC3 $(C)$ and tubulin $(D)$ with normal $\mathrm{IgG}$ show no fluorescence staining. (b) Dual-staining of LC3 ( $A$; FITC) and FN mRNA ( $B$; rhodamine) in cultured DA SMC. Like LC3 staining, the majority of FN mRNA staining was also found in the perinuclear area. Under the dual filter, the two signals show some overlap $(C)$. Controls for LC3 staining using normal IgG and for RNA staining by predigestion of RNA with RNase A show only nuclear staining by DAPI $(D)$. Bar $=10 \mu \mathrm{m}$. 
a

\begin{tabular}{|c|c|c|c|c|c|}
\hline \multicolumn{3}{|c|}{ DA } & \multicolumn{2}{|r|}{ Ao } & \multirow[b]{2}{*}{$(\mu \mathrm{g} / \mathrm{ml})$} \\
\hline 0 & 1.67 & 5 & 0 & 1.675 & \\
\hline - & - & - & - & $-\infty$ & LC3 \\
\hline icen & $=$ & 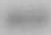 & & 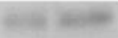 & FN \\
\hline
\end{tabular}

b

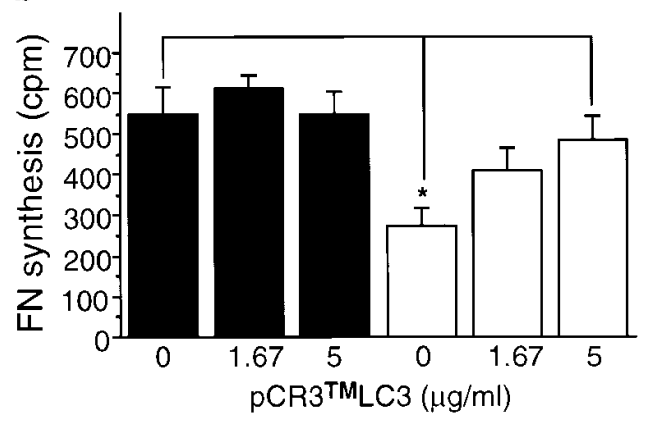

C

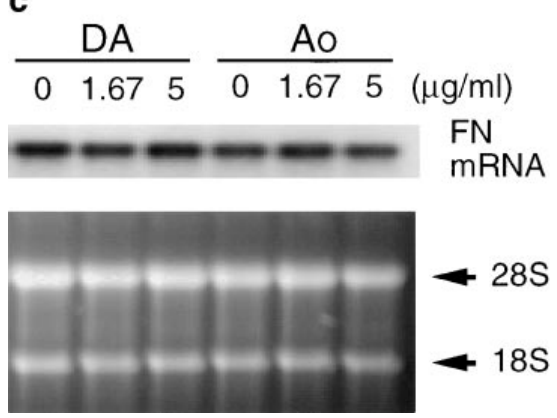

Figure 9. Overexpression of LC3 in Ao SMC enhances FN mRNA translation. (a) A representative Western blot shows that transfection of LC3 by the adenovirus component system (see Methods) increased LC3 production in a dose-dependent manner in Ao but only partially in DA cells (top). The overexpression of LC3 in Ao cells also augmented FN synthesis to the levels observed in the DA cells, whereas this was not associated with a significant increase in FN synthesis in DA cells (bottom). The concentration of plasmid, pCR $^{\circledR}$-LC3, used in the transfection is indicated at the top. (b) Graph of quantitative assessments of FN synthesis from four different experiments showing that there is a significant decrease in the basal level of newly synthesized FN in Ao (white bars) compared with DA cells (black bars). $* P<0.05$, SuperANOVA and Duncan's test of multiple comparisons. However, the newly synthesized FN in Ao cells is increased significantly after transfection with pCR ${ }^{\circledR}$-LC3 $(P<0.05)$ in a dose-dependent manner. (c) Northern blot analysis indicating that there is no change in the level of FN mRNA after LC3 transfection compared with controls in either DA or Ao cells. The loading condition is demonstrated by ethidium bromide staining of $18 \mathrm{~S}$ and $28 \mathrm{~S}$.

we have shown that the ARE in the $3^{\prime}$ UTR of FN mRNA is the functional cis-acting element, and have purified and identified the trans-acting factor as MAP1 LC3. Several lines of evidence led us to believe that binding of LC3 to the ARE in FN mRNA is functionally involved in its translation. First, the ARE is involved in CAT-FN 3'UTR fusion mRNA translation. Second, there is increased ARE-binding activity and expression of LC3 in DA compared with Ao SMC, associated with increased FN mRNA translation. Third, LC3 codistributes with FN mRNA in the perinuclear region of cells. Finally, overexpression of LC3 in Ao SMC enhances FN mRNA translation to levels observed in the DA cells.

We related the mechanism of posttranscriptional regulation of FN expression to the ARE by transfecting constructs containing the CAT coding region and downstream FN 3'UTR into primary cultured SMC. Our findings suggested that the ARE in the $3^{\prime} \mathrm{UTR}$ of FN mRNA decreases mRNA stability while enhancing mRNA translation, and are consistent with previous work indicating that degradation of mRNA by GMCSF and c-fos ARE is coupled with ongoing translation or ribosome binding $(28,30)$. This may be related to translationaldependent assembly of a $>20$ S degradation complex (29). Since others have described the ARE as a repressor of mRNA translation (24-27), the difference between our findings and theirs may be due to several factors. First, our experimental system used primary cultured vascular SMC and investigated ARE function in the entire 3'UTR of FN mRNA. Second, the ARE may function as a repressor or an enhancer of translation, depending on binding of specific cytoplasmic factors. In parallel studies, we have shown that LC3 is absent from HT 1080 fibrosarcoma cells, which produce low levels of FN. Stable transfection of LC3 in HT 1080 cells results in increased translation of FN mRNA due to enhanced ribosomal recruitment, and is associated with reversion to a slower-growing phenotype (our unpublished observations).

The functional existence of ARE-binding factors was suggested when we compared FN expression and cell shape in DA cells transfected with CAT-FN 3'UTR fusion constructs con- taining wild or mutated ARE. Since the elongated motile phenotype of DA cells is dependent on the increased FN expression $(4,5)$, we reasoned that the alteration of cell shape may be due to a reduction of FN expression by sequestering AREbinding factors that would otherwise influence endogenous FN mRNA translation. However, we could not rule out the possibility that sequestration of these putative factors would also prevent binding to other endogenous ARE-containing mRNAs. This could also affect their stability or translation, thereby causing a change in cell phenotype.

Using gel mobility shift assays, we observed that the cytoplasmic proteins in SMC form three binding complexes with the FN 3'UTR, but only one of them is related specifically to the ARE. There was increased binding complex formation in DA compared with Ao SMC, especially after serum stimulation when we used ARE-containing RNA oligonucleotide probes. This suggests that the increased binding to the ARE may be responsible for the increased translation of mRNA in DA SMC, since serum stimulation upregulates FN protein synthesis in DA but not Ao SMC without changing its mRNA level (6). In UV-cross-linking studies, we identified three binding complexes with molecular masses at $\sim 15,30$, and $60 \mathrm{kD}$, and suggested that the high molecular mass complexes may, in fact, result from multimerization of the $15-\mathrm{kD}$ protein through disulfide bonds. This feature has not been described for other AUBFs, and suggested a unique protein or a unique interaction which could result in the enhancement of translation.

The 15-kD ARE-binding factor was purified using sequential ion-exchange and heparin chromatography. Amino-terminal sequence analysis of 10 amino acids revealed a peptide sequence with $100 \%$ homology to rat MAP1 LC3 (37), which, indeed, is a different protein from other AUBFs purified or cloned to date. Similar to AUH, an affinity-purified AREbinding protein using an (AUUUA)6 affinity column (35), computer analysis (MOTIFS; GCG) failed to identify RNAbinding motifs in LC3 protein that are present in other RNA-binding proteins. However, LC3 is a basic protein with a predicted pI of 9.2 and arginine-rich sequences similar to argi- 
nine-rich RNA-binding proteins (46). The arginine-rich sequence (RRSFEQRVEDVRLIR) close to the amino terminus may form an RNA-binding site.

We used purified bacterially-expressed recombinant LC3 to confirm its binding for the 3'UTR of FN mRNA. Moreover, LC3 appears to bind specifically to the ARE within the 3'UTR. The fact that overexpression of LC3 in Ao SMC optimizes FN mRNA translation provides direct evidence supporting the interaction of LC3 and the ARE in the 3'UTR of FN mRNA as responsible for upregulation of FN mRNA translation in primary cultured DA SMC. In further studies, we confirmed LC3 coexpression with FN protein in the motile SMC in the intima cushion of DA tissues (our unpublished data).

Many mRNAs appear to be sorted within cells through the microtubules or other cytoskeletal elements, suggesting that translation can be affected by intracellular transport and localization of mRNA (47-49). Signals that direct intracellular transport and localization of mRNAs are also found within the 3'UTR of mRNA (50-52). Interactions between microtubules and mRNA may be linked by factors which recognize consensus sequences in RNA, as well as bind to microtubules. MAPs are good candidates for these factors. Two RNA-binding proteins have been reported to bind microtubules. In male germ cells, spermatid perinuclear RNA-binding protein, which binds to the 3'UTR of spermatid-specific protamine- 1 mRNA, is localized to microtubules and was proposed to be involved functionally in RNA transport or translational activation (53). It was also found that testis/brain RNA-binding protein attaches to translationally repressed and transported mRNAs, such as protamine-2, tau, and myelin basic protein, and to microtubules (54). Like spermatid perinuclear and testis/brain RNAbinding proteins, the high expression of LC3 in the brain is consistent with the role LC3 may play in regulating brain mRNA transport and localization as well. The finding that LC3 is an ARE-binding protein suggests that control of immediate early gene mRNA stability or translation may also be mediated by mRNA transport or storage.

Our results extend previous findings that the ARE in the 3'UTR plays an important role in regulating the stability and translation of labile mRNAs, such as cytokines and protooncogenes, by showing that this element controls the translation of more stable mRNAs of extracellular matrix proteins. By using primary cell cultures that maintain distinct phenotypic properties in vitro, we have identified LC3 as a trans-acting factor which appears to regulate the high levels of FN synthesis in migratory DA SMC, and which was not known previously to have RNA-binding properties. Thus, this report elucidates the role of a microtubule-binding protein in mRNA translation and provides new insights into the molecular basis regulating expression of FN, a glycoprotein with numerous functions related to cell growth, differentiation, and migration in development and disease.

\section{Acknowledgments}

The authors are grateful to Ms. Susy Taylor and Joan Jowlabar for secretarial assistance in preparing the manuscript, and to Mr. Michael Starr for photography. We also thank Drs. Fred Keeley, Dennis Wigle, Tim Childs, Quirong Li, Peter Lloyed Jones, and Syed Zaidi for helpful discussion.

This work was supported by Program Grant MT8546 from the Medical Research Council of Canada (M. Rabinovitch) and U.S.
Public Health Service grant NS-30985 (J. Hammarback). M. Rabinovitch is a Chair in Cardiovascular Sciences of the Heart and Stroke Foundation of Ontario.

\section{References}

1. Gittenberger-de-Groot, A.C., J.L.M. Strengers, M. Mentink, R.E. Poelmann, and D.F. Patterson. 1985. Histologic studies on normal and persistent ductus arteriosus in the dog. J. Am. Coll. Cardiol. 6:394-404.

2. Gittenberger-de-Groot, A.C., A.J.M. Moulaert, and J.F. Hitchcock. 1980. Histology of the persistent arteriosus in cases of congenital rubella. Circulation. 62:183-186.

3. Gittenberger-de-Groot, A.C., I. Ertbruggen, A.J.M. Moulaert, and E. Harinck. 1980. The ductus arteriosus in the preterm infant: histologic and clinical observations. J. Pediatr. 96:88-93.

4. Boudreau, N., and M. Rabinovitch. 1991. Developmentally regulated changes in extracellular matrix in endothelial and smooth muscle cells in the ductus arteriosus may be related to intimal proliferation. Lab. Invest. 64:187-199.

5. Boudreau, N., E.A. Turley, and M. Rabinovitch. 1991. Fibronectin, hyaluronan and a hyaluronan binding protein contribute to increased ductus arteriosus smooth muscle migration. Dev. Biol. 143:235-247.

6. Boudreau, N., N. Clausell, J. Boyle, and M. Rabinovitch. 1992. Transforming growth factor-beta regulates increased ductus arteriosus endothelial glycosaminoglycan synthesis and a post-transcriptional mechanism controls increased smooth muscle fibronectin, features associated with intimal proliferation. Lab. Invest. 67:350-359.

7. Hynes, R.O., and A.D. Lander. 1992. Contact and adhesive specificities in the associations, migration, and targeting of cells and axons. Cell. 68:303-322.

8. Dean, D.C., M.S. Blakeley, R.F. Newby, P. Ghazal, L. Hennighausen, and S. Bourgeois. 1989. Forskolin inducibility and tissue-specific expression of the fibronectin promoter. Mol. Cell. Biol. 9:1498-1506.

9. Penttinen, R., S. Kobayashi, and P. Bornstein. 1988. Transforming growth factor $\beta$ increases mRNA for matrix proteins both in the presence and in the absence of changes in mRNA stability. Proc. Natl. Acad. Sci. USA. 85: 1105-1108.

10. Ffrench-Constant, C., L. Van De Water, H.F. Dvorak, and R.O. Hynes. 1989. Reappearance of an embryonic pattern of fibronectin splicing during wound healing in the adult rat. J. Cell Biol. 109:903-914.

11. Glukhova, M.A., M.G. Frid, B.V. Shekhonin, T.D. Vasilevskaya, J. Grunwald, M. Saginati, and V.E. Koteliansky. 1989. Expression of extra domain A fibronectin sequence in vascular smooth muscle cells is phenotype dependent. J. Cell Biol. 109:357-366.

12. Rasoamanantena, P., R. Thweatt, J. Labat-Robert, and S. Goldstein. 1994. Altered regulation of fibronectin gene expression in Werner syndrome fibroblasts. Exp. Cell Res. 213:121-127.

13. Chou, L., J.D. Firth, V.-J. Uitto, and D.M. Brunette. 1995. Substratum surface topography alters cell shape and regulates fibronectin mRNA level, mRNA stability, secretion and assembly in human fibroblasts. J. Cell Sci. 108: 1563-1573.

14. Dean, D.C., R.F. Newby, and S. Bourgeois. 1988. Regulation of fibronectin biosynthesis by dexamethasone, transforming growth factor $\beta$, and cAMP in human cell lines. J. Cell. Biol. 106:2159-2170.

15. Chandler, L.A., and S. Bourgeois. 1991. Posttranscriptional down-regulation of fibronectin in N-ras-transformed cells. Cell Growth Differ. 2:379-384.

16. Klausner, R.D., and J.B. Harford. 1989. cis-trans models for posttranscriptional gene regulation. Science. 246:870-873.

17. Caput, D., B. Beutler, K. Hartog, S. Brown-Shimer, and A. Cerami. 1986. Identification of a common nucleotide sequence in the $3^{\prime}$-untranslated region of mRNA molecules specifying inflammatory mediators. Proc. Natl. Acad. Sci. USA. 83:1670-1675.

18. Kornblihtt, A.R., K. Vibe-Pedersen, and F.E. Baralle. 1983. Isolation and characterization of cDNA clones for human and bovine fibronectins. Proc. Natl. Acad. Sci. USA. 80:3218-3222.

19. Schwarbauer, J.E., J.W. Tamkun, I.R. Lemischka, and R.O. Hynes 1983. Three different fibronectin mRNAs arise by alternative splicing within the coding region. Cell. 35:421-431.

20. Jones, T.R., and M.D. Cole. 1987. Rapid cytoplasmic turnover of c-myc mRNA: requirement of 3' untranslated sequences. Mol. Cell. Biol. 7:4513-4519.

21. Shaw, G., and R. Kamen. 1986. A conserved AU sequence from the $3^{\prime}$ untranslated region of GM-CSF mRNA mediates selective mRNA degradation. Cell. 46:659-667.

22. Shyu, A.-B., J.G. Belasco, and M.E. Greenberg. 1991. Two distinct destabilizing elements in the c-fos message trigger deadenylation as a first step in rapid mRNA decay. Genes Dev. 5:221-231.

23. Wilson, T., and R. Treisman. 1988. Removal of poly(A) and consequent degradation of c-fos mRNA facilitated by AU-rich sequences. Nature. 336:396-399.

24. Kruys, V., O. Marinx, G. Shaw, J. Deschamps, and G. Huez. 1989. Translational blockade imposed by cytokine-derived UA-rich sequences. Science. 245:85-88.

25. Kruys, V., M. Wathelet, P. Poupart, R. Contreras, W. Fiers, J. Content, 
and G. Huez. 1987. The $3^{\prime}$ untranslated region of the human interferon- $\beta$ mRNA has an inhibitory effect on translation. Proc. Natl. Acad. Sci. USA. 84: 6030-6034.

26. Grafi, G., I. Sela, and G. Galili. 1993. Translational regulation of human beta interferon mRNA: association of the $3^{\prime}$ AU-rich sequence with the poly(A) tail reduces translation efficiency in vitro. Mol. Cell. Biol. 13:34873493.

27. Han, J., T. Brown, and B. Beutler. 1990. Endotoxin-responsive sequences control cachectin/tumor necrosis factor biosynthesis at the translational level. J. Exp. Med. 171:465-475.

28. Aharon, T., and R.J. Schneider. 1993. Selective destabilization of shortlived mRNAs with the granulocyte-macrophage colony-stimulating factor AUrich $3^{\prime}$ noncoding region is mediated by a cotranslational mechanism. Mol. Cell. Biol. 13:1971-1980.

29. Savant-Bhonsale, S., and D.W. Cleveland. 1992. Evidence for instability of mRNAs containing AUUUA motifs mediated through translation-dependent assembly of a $>20$ S degradation complex. Genes Dev. 6:1927-1939.

30. Winstall, E., M. Gamache, and V. Raymond. 1995. Rapid mRNA degradation mediated by the c-fos 3' AU-rich element and that mediated by the granulocyte-macrophage colony-stimulating factor $3^{\prime}$ AU-rich element occur through similar polysome-associated mechanisms. Mol. Cell. Biol. 12:29312940.

31. Malter, J.S. 1989. Identification of an AUUUA-specific messenger RNA binding protein. Science. 246:664-666.

32. Bohjanen, P.R., B. Petryniak, C.H. June, C.B. Thompson, and T. Lindsten. 1992. AU RNA-binding factors differ in their binding specificities and affinities. J. Biol. Chem. 267:6302-6309.

33. Levine, T.D., F. Gao, P.H. King, L.G. Andrews, and J.D. Keene. 1993. Hel-N1: an autoimmune RNA-binding protein with specificity for $3^{\prime}$ uridylaterich untranslated regions of growth factor mRNAs. Mol. Cell. Biol. 13:34943504.

34. Ma, W.-J., S. Cheng, C. Campbell, A. Wright, and H. Furneaux. 1996. Cloning and characterization of HuR, a ubiquitously expressed Elav-like protein. J. Biol. Chem. 271:8144-8151.

35. Nakagawa, J., H. Waldner, S. Meyer-Monard, J. Hofsteenge, P. Jeno, and C. Moroni. 1995. AUH, a gene encoding an AU-specific RNA binding protein with intrinsic enoyl-CoA hydratase activity. Proc. Acad. Natl. Sci. USA. 92: 2051-2055.

36. Zhang, W., B.J. Wagner, K. Ehrenman, A.W. Schaefer, C.T. DeMaria, D. Crater, K. DeHaven, L. Long, and G. Brewer. 1993. Purification, characterization, and cDNA cloning of an AU-rich element RNA-binding protein, AUF1. Mol. Cell. Biol. 13:7652-7665.

37. Mann, S.S., and J.A. Hammarback 1994. Molecular characterization of light chain 3: a microtubule binding subunit of MAP1A and MAP1B. J. Biol. Chem. 269:11492-11497.

38. Rabinovitch, M., S. Beharry, T. Bothwell, and G. Jackowski. 1988. Qualitative and quantitative differences in protein synthesis comparing fetal lamb ductus arteriosus endothelium and smooth muscle with cells from adja- cent vascular sites. Dev. Biol. 130:250-258.

39. Luckow, B., and G. Schütz. 1987. CAT constructions with multiple unique restriction sites for the functional analysis of eukaryotic promoters and regulatory elements. Nucleic Acids Res. 15:5490.

40. Ellis, L., E. Clauser, D.O. Morgan, M. Edery, R.A. Roth, and W.J. Rutter. 1986. Replacement of insulin receptor tyrosine residues 1162 and 1163 compromises insulin-stimulated kinase activity and uptake of 2-deoxyglucose. Cell. 45:721-732.

41. Milligan, J.F., D.R. Groebe, G.W. Witherell, and O.C. Uhlenbeck. 1987. Oligoribonucleotide synthesis using T7 RNA polymerase and synthetic DNA templates. Nucleic Acids Res. 15:8783-8797.

42. Sambrook, J., E.F. Frisch, and T. Maniatis. 1989. Molecular Cloning: A Laboratory Manual. Vol. 3. Cold Spring Harbor Laboratory, Cold Spring Harbor, NY.

43. Kohout, T.A., J.J. O'Brian, S.T. Gaa, W.J. Lederer, and T.B. Rogers. 1996. Novel adenovirus component system that transfects cultured cardiac cells with high efficiency. Circ. Res. 78:971-977.

44. Bassell, G.J., C.M. Powers, K.L. Taneja, and R.H. Singer. 1994. Single mRNAs visualized by ultrastructural in situ hybridization are principally localized at actin filament intersections in fibroblasts. J. Cell Biol. 126:863-876.

45. Malter, J.S., and Y. Hong. 1991. A redox switch and phosphorylation are involved in the post-translational up-regulation of the adenosine-uridine binding factor by phorbol ester and ionophore. J. Biol. Chem. 266:3167-3171.

46. Burd, C.G., E.L. Matunis, and G. Dreyfuss. 1991. The multiple RNAbinding domains of the mRNA poly(A)-binding protein have different RNAbinding activities. Mol. Cell. Biol. 11:3419-3424.

47. Singer, R.H. 1992. The cytoskeleton and mRNA localization. Curr Opin. Cell Biol. 3:719-721.

48. St. Johnston, D. 1995. The intracellular localization of messenger RNAs. Cell. 81:161-170.

49. Suprenant, K.A. 1993. Microtubules, ribosomes, and RNA: evidence for cytoplasmic localization and translational regulation. Cell Motil. Cytoskeleton. 25:1-9.

50. Kislauskis, E.H., X. Zhu, and R.H. Singer. 1994. Sequence responsible for intracellular localization of $\beta$-actin messenger RNA also affects cell phenotype. J. Cell Biol. 127:441-451.

51. Kim-Ha, J., K. Kerr, and P.M. Macdonald. 1995. Translational regulation of oskar mRNA by Bruno, an ovarian RNA-binding protein, is essential. Cell. 81:403-412.

52. Ferrandon, D., L. Elphick, C. Nusslein-Volhard, and D. St. Johnston. 1994. Staufen protein associates with the $3^{\prime}$ UTR of bicoid mRNA to form particles that move in a microtubule-dependent manner. Cell. 79:1221-1232.

53. Schumacher, J.M., K. Lee, S. Edelhoff, and R.E. Braun. 1995. Spnr, a murine RNA-binding protein that is localized to cytoplasmic microtubules. $J$. Cell Biol. 129:1023-1032.

54. Han, J.R., G.K. Yiu, and N.O. Hecht. 1995. Testis/brain RNA-binding protein attaches translationally repressed and transported mRNAs to microtubules. Proc. Natl. Acad. Sci. USA. 92:9550-9554. 